\title{
Do countries free ride on MFN? ${ }^{\text {is }}$
}

\author{
Rodney D. Ludema ${ }^{\mathrm{a}, *}$, Anna Maria Mayda ${ }^{\mathrm{a}, \mathrm{b}}$ \\ a Department of Economics and School of Foreign Service, Georgetown University, Washington, DC 20057, USA \\ b $C E P R, U K$
}

\section{A R T I C L E I N F O}

\section{Article history:}

Received 27 July 2007

Received in revised form 7 March 2008

Accepted 12 August 2008

Available online $\mathrm{xxxx}$

\begin{abstract}
A B S T R A C T
The Most-Favored Nation (MFN) clause has long been suspected of creating a free rider problem in multilateral trade negotiations. To address this issue, we model multilateral negotiations as a mechanism design problem with voluntary participation. We show that an optimal mechanism induces only the largest exporters to participate in negotiations over any product, thus providing a rationalization for the Principal supplier rule. We also show that, through this channel, equilibrium tariffs vary according to the HerfindahlHirschman index of export shares: higher concentration in a sector reduces free riding and thus causes a lower tariff. Estimation of our model using sector-level tariff data for the U.S. provides strong support for this relationship.
\end{abstract}

(c) 2008 Elsevier B.V. All rights reserved.

\section{Introduction}

The Most-Favored Nation (MFN) clause has been a central element of international trade agreements for over a hundred years ${ }^{1}$ and is widely acknowledged as one of the "pillars" of the GATT/WTO system. Found in almost all WTO agreements, the MFN clause requires that each member give equal treatment to the same goods or services of all other members in the application of its trade policy. In practice, MFN implies that every time a country lowers a trade barrier or opens up a market, it must do so for the same goods or services from all its WTO trading partners. Despite the prominence of MFN, its actual effect on the progress of trade liberalization within the multilateral system remains largely unknown.

A spate of recent theoretical literature has pointed to several potential benefits of the MFN clause, deriving mainly from its ability to curb opportunistic behavior by governments that might otherwise undermine trade agreements. ${ }^{2}$ This paper does not address these arguments; rather, we focus on the most notable and long-standing concern about MFN, which is that it opens the

\footnotetext{
We especially thank Bruce Blonigen, Chad Bown, Brian Copeland, Peter Debaere, Nuno Limão and Robert Staiger for helpful comments on earlier drafts, and we thank seminar participants at KU Leuven, University of British Columbia, University of Oregon, University of Maryland, University of Geneva, Georgetown, Stanford, Università di Milano, Ente Einaudi, Inter-American Development Bank, the 2005 NBER Summer Institute Conference, the CEPR ERWIT Conference in Rotterdam, the 2005 EIIT Conference, and the Midwest International Economics Conference.

* Corresponding author.

E-mail addresses: ludemar@georgetown.edu (R.D. Ludema), amm223@georgetown.edu (A.M. Mayda).

${ }^{1}$ See Caplin and Krishna (1988) for a detailed history of MFN.

2 Examples include, Choi (1995), Ethier (2004), Ludema and Cebi (2005), Bagwell and Staiger (2002, Ch. 5), Ederington and McCalman (2003), Saggi (2004); see Horn and Mavroidis (2001) for a survey.
}

possibility of countries "free riding" on the trade negotiations of others. $^{3}$ This concern stems from the fact that whenever a few WTO members mutually exchange trade-barrier reductions, they must extend those reductions to all other WTO members under MFN, even if the latter do not reciprocate. To the extent that nonreciprocating countries benefit from improved market access to liberalizing countries (the so-called MFN externality), two related incentive problems emerge: countries may avoid participating in negotiations in hopes of free riding on the liberalization of others; and countries that do enter negotiations may reach inefficient agreements, as they do not fully internalize the benefits of their liberalization.

This paper aims to provide an empirical assessment of the MFN free rider problem based on theory. We are interested in how MFN shapes countries' participation decisions ${ }^{4}$ and ultimately their tariffs. Unfortunately, there are no data on participation decisions at the relevant level of specificity. Thus, we develop a theoretical model, which allows us to identify the MFN-free-rider component of a country's tariff schedule based solely on observable data from the market for each product. In the process, we derive several theoretical results that are of independent interest.

\footnotetext{
${ }^{3}$ Viner (1924) cites John Jay, who in a 1787 report to Congress concerning the U.S.Netherlands Treaty of 1782, expressed the U.S. position on MFN: "it would certainly be inconsistent with the most obvious principles of justice and fair construction, that because France purchases, at a great price, a privilege of the United States, that therefore the Dutch shall immediately insist, not on having the like privileges for the like price, but without any price at all." The U.S. would not fully embrace unconditional MFN in trade treaties until 1923.

${ }^{4}$ Participation decisions refer here to the choices of existing WTO members to participate or not in periodic negotiations for the reduction of trade barriers on specific products. It does not refer to the much larger decision of whether or not to join the WTO.
} 
We consider a multi-country model with one importer and several exporters of a given product. We assume each country is free to participate or not in negotiations aimed at cutting the importer's MFN tariff. We assume that any resulting agreement is Pareto efficient for participants (i.e., for the importer and participating exporters) but also benefits non-participating exporters via the MFN externality. Given these assumptions, we show that it is impossible to design a system of trade negotiations in which all countries participate, unless exporter concentration, as measured by the Herfindahl-Hirshman index (sum of squared export shares) is sufficiently high. The reason this index matters is that each exporting country's willingness to participate in negotiations is approximately proportional to its squared market share, reflecting the product of two effects: the effect that the exporter's participation has on the size of the negotiated tariff cut and the effect that the tariff cut has on the exporter's welfare.

Our second theoretical finding is that any system of trade negotiations that maximizes world welfare subject to the above assumptions induces the participation of only the largest exporters of the product. This prediction accords with both anecdotal evidence on free riding found in earlier work and with a WTO negotiating convention, known as the "principal supplier rule." The principal supplier rule is a key aspect of the item-by-item, request-and-offer method that has been GATT's most common form of negotiation over the years. ${ }^{5}$ It basically mandates that a country's tariff on each product be negotiated with the exporters having a "principal supplying interest" in the country's market for that product. Normally this is taken to mean the largest exporter, or group of exporters, as measured by market share. ${ }^{6}$ We show that such a rule is an optimal response to the MFN free rider problem. In a situation where full participation is not possible, it is beneficial to have the countries that do participate be principal suppliers as this minimizes the MFN externality, thereby producing the lowest negotiated tariffs.

Finally, our model predicts that the level of the importer's tariff resulting from negotiations should be negatively related to the Herfindahl-Hirshman index (HHI) on a product-by-product basis. This is the finding we take to the data. We derive an estimating equation from our model, suitable for explaining tariffs across sectors. Using US MFN tariff rates for both 1983 (following the Tokyo Round) and 1989-1999 (during and after the Uruguay Round), we find strong evidence of this negative relationship, controlling for the other determinants of MFN tariff rates suggested by the theoretical model (domestic political-economy determinants and the export market share of FTA partners). Endogeneity is addressed by adding controls, using instrumental variables, estimating the effect of the HHI on nontariff barriers in addition to tariffs, and by examining tariff differences between rounds.

\footnotetext{
${ }^{5}$ In the Uruguay round, the US used the item-by-item approach. On the other hand, the Kennedy and Tokyo Rounds were characterized by a formula approach, whereby each country cuts tariffs across-the-board according to a certain formula agreed to at the outset. In fact, however, countries deviated considerably from the formula cuts on an item-by-item basis, and many countries ignored the formula entirely (Hoda, 2001, pp. 30-32). Negotiations over these deviations took place on an item-by-item basis between principal suppliers. According to Hoda (2001, p. 47), "Thus a linear or formula approach did not obviate the need for bilateral negotiations: they only gave the participants an additional tool to employ in the bargaining process."

${ }^{6}$ The original guideline of the Preparatory Committee (1946) was that products should be negotiable only if the participants, individually or as a group, supply a "principal part of the total imports of a particular product to a particular member country" (p.6). This is clarified in Article XXVIII: when a country wishes to modify or withdraw a concession previously granted, it must negotiate compensation with, 1) those countries with which the concession was originally negotiated, and 2) those countries with a principal supplying interest, defined as having market share larger than any country in category 1) or as otherwise determined by the Ministerial Conference (Hoda, 2001, p. 14). Thus, Article XXVIII implies that the country granting the original concession becomes liable to compensate principal suppliers for modifications or withdraw.
}

\section{Approaches to the MFN free-rider problem}

The logic of the MFN free rider problem rests on two premises. First, there must be free riders - countries that do not fully participate in negotiations. Second, there must be an MFN externality. That is, the MFN tariff reductions of the participants must improve the terms of trade of the free riders. Early theoretical models of the MFN free rider problem, such as Johnson (1965) and Caplin and Krishna (1988), assumed both of these to be true and established that the resulting tariffs negotiated by participants would indeed be inefficiently high.

Several papers have called into question these premises.Viner (1931), for example, noted that countries often try to minimize the MFN externality by defining products so narrowly as to make MFN nonbinding. ${ }^{7}$ In the extreme, if products are defined in such a way that no product is imported from more than one country, then the MFN externality cannot exist. More recently, Bagwell and Staiger (2002, Ch.5) have argued that the MFN externality can be suppressed if participants adhere to the principle of reciprocity, defined as mutual changes in trade policy such that, for each participant, changes in import and export volumes are equal at original world relative prices. They show that such trade policy changes have the effect of holding constant world relative prices, and thus free riders do not ultimately benefit from the trade policy changes negotiated by participants. Finally, Ludema (1991) showed that countries may not actually free ride, even if the MFN externality exists. He put forth a model of multilateral bargaining, in which countries have the option of free riding but choose not to do so in equilibrium. This occurs because free riding by one country triggers a temporary breakdown in negotiations, which amounts to an effective punishment of free riders. Thus, in this model, the structure of the multilateral negotiations causes the MFN externality to be internalized. ${ }^{8}$

Whether or not these means of curtailing the MFN free rider problem are entirely effective in practice is an open question. Prima facie evidence suggests they may not be. In practice, manipulation of product classification is limited under the harmonized classification system, and we know from the data that most imported products into the U.S. are supplied by more than one country at the tariff line level. As for reciprocity, little is known about how strictly countries adhere to this rule in trade negotiations. Although Preeg (1970) contends that negotiators in the Kennedy Round tried to balance expected changes in imports and exports, Finger et al. (2002) find evidence to the contrary in the Uruguay Round. ${ }^{9}$ In general the implementation of reciprocity requires a great deal of information as well as a complete set of trade policy instruments, i.e., both import tariffs and export taxes, positive and negative (see Bagwell and Staiger, 2002, Appendix B). Yet import subsidies and export taxes are rare in practice, and export subsidies are banned under the GATT.

Finally, there is ample evidence that not all countries participate in trade negotiations on all goods, even during multilateral negotiating

\footnotetext{
The oft-cited example is the German-Swiss treaty of 1904 in which tariffs were reduced on "large dapple mountain cattle or brown cattle reared at a spot at least 300 metres above sea level and having at least one month's grazing each year at a spot at least 800 metres above sea level" (Viner, 1931 p. 101, as quoted in Caplin and Krishna, 1988, p269).

${ }^{8}$ Recent theoretical literature on the effect of MFN on multi-country bargaining has focused on sequential bilateral bargaining (Bagwell and Staiger, 2004; Bond, Ching, and Lai, 2003) and asymmetric information (McCalman, 2002; Ludema and Cebi, 2001). In each case, the MFN externality continues to exert an effect, though not always in the form of free riding.

${ }^{9}$ None of the Uruguay Round negotiating delegations they surveyed attempted to calculate concessions received from other countries, and calculations by the authors suggested large imbalances between tariff concessions given and received. By contrast, Karacaovali and Limao (2008) find that in the Uruguay Round, the EU did make deeper tariff cuts on those products whose principal suppliers made larger tariff cuts on EU exports. However, both of these studies compare trade-weighted averages of tariff cuts given and received, rather than changes in trade volumes, so they do not accurately test of whether reciprocity in the sense of Bagwell and Staiger (2002) was achieved.
} 
rounds ${ }^{10}$ in contrast to Ludema (1991). Finger (1979) provides evidence that participation affected US tariff concessions in the first six GATT rounds (1947-1967). He found that the share of imports originating in participating countries of goods on which the US granted tariff cuts was consistently larger than those countries' share in total US imports. His interpretation is that the US selected goods for tariff cuts so as to internalize the benefits to the participants. Examining a cross-section of U.S. pre-Tokyo tariffs, Lavergne (1983) finds higher tariffs on goods exported predominantly by LDCs, controlling for various domestic political factors. He offers an MFN interpretation of this finding as well. A limitation of these studies is that they do not consider the possibility of selective participation, i.e., participating in negotiations on some items but not others, ${ }^{11}$ or that such decisions might be endogenous.

All of this provides motivation for a careful, model-based empirical investigation of the MFN free rider problem. It also suggests an approach to the problem, which is to ask what the MFN free rider problem should look like in a world where narrow product classification, reciprocity, and free rider punishments do not constrain it. Our model provides a simple answer: the extent of free riding is determined by the degree of exporter concentration in the home import market. Of course, this relationship may be quite hard to identify in the data, if these factors actually do constrain. The fact that we find robust empirical evidence consistent with our prediction, therefore, we take as strong evidence that the MFN free rider problem persists.

\section{The model}

There are $\mathrm{N}+1$ countries, indexed by $\mathrm{i}=0, \ldots, \mathrm{N}$, and two goods, $\mathrm{X}$ and Y, produced under constant returns to scale and perfect competition. Good Y is the numeraire and employs only labor, while $\mathrm{X}$ employs both labor and a sector-specific factor K, according to the production function $X=g(K, L)$. Preferences are identical across countries, according to the quasi-linear per capita utility function, $U=c_{Y}+u\left(c_{X}\right)$, where $u^{\prime}>0, u^{\prime \prime}<0$. The endowments of country $i$ are given by $\mathrm{K}_{\mathrm{i}}$ and $\mathrm{L}_{\mathrm{i}}$, and let $\mathrm{k}_{\mathrm{i}} \equiv \mathrm{K}_{\mathrm{i}} / \mathrm{L}_{\mathrm{i}}$. We assume endowments are such that country 0 is the importer of good $X$ and the other $\mathrm{N}$ countries are exporters.

Each government seeks to maximize a weighted social welfare function, with weight $\lambda$ reflecting the greater importance of specificfactor owners in its domestic political process. As Baldwin (1987) notes, this is consistent with a wide range of political economy models. Letting $S$ denote per capita consumer surplus, $\pi$ the return to the specific factor, and $M$ net imports, the government welfare functions are given by,

$w_{0}=L_{0}\left[1+S(p)+\left(1+\lambda_{0}\right) \pi(p) k_{0}\right]+\left(p-p^{*}\right) M_{0}(p)$

$w_{i}=L_{i}\left[1+S\left(p^{*}\right)+\left(1+\lambda_{i}\right) \pi\left(p^{*}\right) k_{i}\right]$ for $i=1, \ldots, N$

The domestic and foreign prices are $p$ and $p^{*}$, respectively.

\footnotetext{
${ }^{10}$ Horn and Mavroidis (2000) note that "...In the WTO, negotiations for the most part take place between subsets of Member countries. Sometimes this is 'officially sanctioned,' as in the case of Principal Supplier negotiations. But also in seemingly multilateral negotiations, the 'actual' negotiations occur between a very limited number of countries..." (Horn and Mavroidis, 2001, p. 34).

11 Finger (1979) and others use the term participant to refer to a country that engages in negotiations on any item, implying that only countries that do not negotiate at all can be regarded as free riders. We take an item-by-item view of participation, consistent with the item-by-item approach. A participant refers to the importer making a concession on a particular good and the exporters that offer compensation for that concession (usually principal suppliers of the good to that importer). While the country-level participation view is empirically straightforward - participants can be identified ex post by looking at which countries submitted schedules of final bound tariffs - it potentially misses a lot of the action at the micro level, and it is completely unhelpful for examining the Uruguay Round, because all countries participated as a condition for joining the WTO (by the so-called Single Undertaking rule). The empirical challenge for us is that detailed information about who negotiated what with whom, and on what terms, is not publicly available at this time, which is why we need a theory to link market characteristics to expected free riding on each product.
}

Although not essential for our results, it is convenient for exposition to impose a degree of symmetry on the exporters. Let $k_{i}=k^{*}$ and $\lambda_{i}=\lambda^{*}$ for all $i=1, \ldots, N$. This enables us to write Eq. (2) as $w_{i}=\theta_{i} w^{*}$, where $w^{*}=\Sigma_{j=1}^{N} w_{j}$ and $\theta_{i}=L_{i} / \Sigma_{j=1}^{N} L_{j}$. We refer to $\theta_{i}$ as the export market share of exporter $i$, as it equals $i$ 's share of world exports of product $X$ to the importing country. Thus, an exporter's welfare is proportional to its market share and market shares are independent of world price. ${ }^{12}$ Henceforth, we index the exporters in descending order of market share.

The importer imposes an ad valorem tariff on good $X$. All countries are assumed to be members of the WTO and are therefore entitled to MFN treatment. Thus, the importer must charge a single, uniform tariff on all imports of $X$, regardless of the source. ${ }^{13}$ To compensate the importer for reductions in its tariff, the exporters must offer concessions in exchange. We allow these concessions to take the form of transfers of good $Y$. The assumption that exporters use transfers, as opposed to reciprocal tariff reductions on other goods, simplifies the analysis in two ways. First, it allows us to abstract from the efficiency consequences of the exporters' policies, which is convenient but not essential for our results. Second, it implies a positive MFN externality from any agreement involving tariff reductions on $X$. The presence of an MFN externality is key.

To determine the tariff and transfers, we need a model of multilateral trade negotiations. One approach is to construct a bargaining game, which attempts to embody the multitude of rules found in actual WTO negotiations; however, this would be a monumental task, not mention a risky one, considering the sensitivity to specification displayed in the bargaining literature. The approach we take here is based on mechanism design theory. The mechanism has a general form, specifying an action space $\sum_{i}$ for each country $i$ and functions $\tau(\cdot)$ and $t(\cdot)$ mapping each action profile $\sigma \in \sum_{1} \times \ldots \times \sum_{n}$ into a tariff $\tau$, measured as one plus the ad valorem tariff rate, and a transfer profile $t=\left(t_{1}, t_{2}, \ldots t_{N}\right)$, respectively. A mechanism is said to implement the outcome $(\tilde{\tau}, \tilde{t}) \in \Re^{N+1}$ if there exists a Nash equilibrium $\sigma$ such that $\tau(\sigma)=\tilde{\tau}$ and $t(\sigma)=\tilde{t}$.

With no restrictions on the set of mechanisms, the WTO could always implement a fully efficient outcome by simply choosing $\tau(\cdot)$ to equal the worldwide efficient tariff for all action profiles. However, we shall restrict attention to mechanisms satisfying the following two conditions:

$(V)$ Voluntary Participation: each country may withdraw from negotiations. If exporter $i$ withdraws, then $t_{i}=0$, regardless of the others' actions, while if the importer withdraws, then $t_{i}=0$ for all $i$ and $\tau$ is set at its unilaterally optimal level $\bar{\tau}$.

$(P)$ Pareto Efficiency for Participants: for all $\sigma, \tau(\sigma)$ maximizes the joint welfare of all countries that do not withdraw.

The first assumption is that no country can be forced from its status quo. The exporters cannot be forced to make positive transfers, and the importer cannot be forced to reduce its tariff. This assumption can be justified by appealing to national sovereignty. The second assumption is that participants will always negotiate an efficient outcome for themselves. Importantly, this means that the participants cannot be made to take part in any scheme to punish free riders with an inefficient (for participants) tariff. One possible justification for this might be renegotiation: if participants were permitted to renegotiate

\footnotetext{
12 Without the symmetry assumptions, it would still be the case that the change in an exporter's welfare is proportional to $\theta_{i}$, i.e., $w_{i}^{\prime}=\theta_{i} w^{* \prime}$, which is the important point. However, $\theta_{i}$ would differ from simple market share, becoming $\theta_{i} \equiv\left(-M_{i}+\lambda_{i} X_{i}\right) / \sum_{j \in N}$ $\left(-M_{j}+\lambda_{j} X_{j}\right)$, and would vary with the world price. None of our theoretical results would change, as long as the price elasticity of $\theta_{i}$ is not too large. In our empirical work, we use simple market shares as a proxy for $\theta_{i}$, since we lack data on the political weights of the exporting countries. Thus, there is ultimately no benefit to using the more general, more complicated, specification.

${ }^{13}$ At this point, we abstract from preferential trade agreements as permitted under Article XXIV. These are dealt with in section IIIE.
} 
the tariff-transfer package after the fact, then no inefficient agreement would survive. In light of these restrictions, we can reduce the action space to two actions, withdraw and not withdraw (i.e., participate), without loss of generality. ${ }^{14}$

\subsection{The negotiated tariff}

In this section, we solve for the tariff that is Pareto efficient for any set of participants, including the importing country. We refer to this as the negotiated tariff. Let $N$ refer to the set of all exporting countries (as well as number of countries in $N$ ), and consider the set $A \subseteq N$. Assuming the importing country and all members of $A$ participate, we can find the negotiated tariff by maximizing $w_{0}(\tau)+\sum_{i \in A} w_{i}(\tau)$ with respect to $\tau$. The first-order condition is,

$w_{0}^{\prime}+\sum_{i \in A} w_{i}^{\prime}=0$.

Differentiating Eqs. (1) and (2) gives,

$w_{0}^{\prime}=\left[\lambda_{0} X_{0}+\left(p-p^{*}\right) \frac{d M_{0}}{d p}\right] \frac{d p}{d \tau}-M_{0} \frac{d p^{*}}{d \tau}$

$\sum_{i \in A} w_{i}^{\prime}=\Theta_{A}\left(M_{0}+\lambda^{*} X^{*}\right) \frac{d p^{*}}{d \tau}$

where $X^{*} \equiv \sum_{i \in N} X_{i}$ is aggregate exporter output, and $\Theta_{A} \equiv \sum_{i \in A} \theta_{i}$ is the cumulative market share of participating exporters. World market clearing implies, $-\mu \frac{d p}{p}=\xi^{*} \frac{d p^{*}}{p^{*}}$, where $\mu$ and $\xi^{*}$ are the elasticities of import demand and total export supply, respectively. Combining this relationship with Eqs. (3)-(5) produces an expression for the negotiated tariff,

$\tau^{n}(A)=\frac{1+\left[1-\Theta_{A}\left(1+\lambda^{*} \frac{X^{*}}{M_{0}}\right)\right] \frac{1}{\xi^{*}}}{\left(1-\frac{\lambda_{0}}{\mu} \frac{X_{0}}{M_{0}}\right)}$.

This tariff reaches a maximum at $\Theta_{A}=0$, which is the unilaterally optimal tariff,

$\bar{\tau} \equiv \tau^{n}(\varnothing)=\left(1+\frac{1}{\xi^{*}}\right) /\left(1-\frac{\lambda_{0}}{\mu} \frac{X_{0}}{M_{0}}\right)$,

and a minimum at $\Theta_{A}=1$, the world efficient tariff,

$\tau^{w} \equiv \tau^{n}(N)=\left(1-\frac{\lambda^{*}}{\xi^{*}} \frac{X^{*}}{M_{0}}\right) /\left(1-\frac{\lambda_{0}}{\mu} \frac{X_{0}}{M_{0}}\right)$.

The negotiated tariff declines as countries are added to the set of participants. This is confirmed by noting that the addition of a country to $A$ increases $\Theta_{A}$, and by total differentiation of Eq. (3), $d \tau^{n} / d \Theta_{A}=w^{* \prime} \mid$ $\left(w_{0}{ }^{\prime \prime}+\sum_{i \in A} w_{i}^{\prime \prime}\right)<0$. This is driven by the terms-of-trade effect of the tariff. The more the terms-of-trade cost of the tariff falls on the participating exporters, as opposed to free riders, the more the total welfare cost of the tariff is internalized in the tariff setting exercise. As the cost to any exporter is proportional to its market share, the share

\footnotetext{
${ }^{14}$ An example of a class of games satisfying $V$ and $P$ are the voluntary participation games of Palfrey and Rosenthal (1984), Saijo and Yamato (1999) and Dixit and Olson (2000), used to analyze public goods provision. They posit a two-stage process, where, in the first stage, agents decide non-cooperatively whether or not to participate. Participants are assumed to share the cost of providing the public good, according to some exogenous sharing rule, while non-participants pay nothing $(V)$. In the second stage, participants engage in efficient bargaining over the level of the public good $(P)$. It can be shown that any outcome that is implementable under $V$ and $P$ is an equilibrium of a voluntary participation game for some sharing rule.
}

of the total cost that falls on participating exporters is $\Theta_{A}$. Thus, the larger the cumulative market share of participating exporters the less beneficial is a tariff to the participant group and the smaller is the negotiated tariff.

Finally, Eq. (6) can be seen as a generalization of several familiar results in the literature. For example, if there were no domestic political pressure $\left(\lambda_{0}=\lambda^{*}=0\right)$, Eq. (7) would just be the standard optimum tariff for a large open economy, while Eq.(8) would equal 1 (free trade). If we were to let, $\lambda_{0}=\frac{I_{L}-\alpha_{L}}{a+\alpha_{L}}$, interpreting $I_{L}$ as an indicator of the political organization of the sector-specific factor, $\alpha_{L}$ as the fraction of voters represented by a lobby, and $a$ as the government's preference for social welfare relative to lobby contributions, then Eqs. (7) and (8) would correspond to the "trade war" and "trade talks" equilibria, respectively, of Grossman and Helpman (1995).

\subsection{Voluntary participation}

Having found the negotiated tariff for any given set of participants, we consider next the question of which countries choose to participate. Suppose $A$ is an equilibrium set of participating exporters. For country $i$ to be a member of this set, the net benefit it receives from participation must exceed the payoff it would receive by withdrawing, given the behavior of all other countries. This means that the transfer $i$ pays must satisfy,

$t_{i} \leq w_{i}\left(\tau^{n}(A)\right)-w_{i}\left(\tau^{n}(A \backslash i)\right)$

The right-hand side of Eq.(9) is the loss in gross welfare exporter $i$ would experience by withdrawing from $A$. This loss is due to an increase in the negotiated tariff from $\tau^{n}(A)$ to $\tau^{n}(A \mid i)$ resulting from $i$ 's withdrawal. We can think of the right-hand side of Eq. (9) as the amount exporter $i$ would be willing to pay to participate.

The right-hand side of Eq. (9) can be approximated by its differential $\theta_{i}^{2} \omega(A)$, where $\omega(A)=-\left(w^{* \prime}\right)^{2} /\left(w_{0}^{\prime \prime}+\sum_{i \in A} w_{\mathrm{i}}^{\prime \prime}\right)>0$ evaluated at $\tau^{n}(A)$. That is, an exporter's willingness to pay is roughly proportional to its squared market share. This is because a country's welfare loss from a small increase in the tariff is proportional to its market share, and so is its impact on the negotiated tariff. The approximation is more accurate the smaller is $\theta_{i}$.

To ensure the participation of the importing country, the sum total of the transfers must be large enough for the importer to forgo its optimal tariff:

$w_{0}\left(\tau^{n}(A)\right)+\sum_{i \in A} t_{i} \geq w_{0}(\bar{\tau})$

Combining Eqs. (9) and (10), it follows that there exists a profile of transfers that supports $A$ as an equilibrium set of participants, if and only if,

$\Omega(A) \equiv \sum_{i \in A} w_{i}\left(\tau^{n}(A)\right)-w_{i}\left(\tau^{n}(A \backslash i)\right)-\left[w_{0}(\bar{\tau})-w_{0}\left(\tau^{n}(A)\right)\right] \geq 0$.

The function $\Omega(A)$ measures the difference between the total willingness to pay of the participating exporters and the opportunity cost to the importing country of imposing the negotiated tariff instead of its optimal tariff. It follows that a tariff $\tau$ can be implemented if and only if $\tau=\tau^{n}(A)$ and $\Omega(A) \geq 0$ for some $A \subset N$.

There are two questions about implementation we can answer immediately. First, is it possible to implement a tariff less than $\bar{\tau}$ ? That is, can the WTO induce at least some participation? The answer is, yes, as can be seen by noting that for any single exporter $i, \Omega(i)=w_{i}\left(\tau^{n}(i)\right)+$ $w_{0}\left(\tau^{n}(i)\right)-\left(w_{i}(\bar{\tau})+w_{0}(\bar{\tau})\right)$. As $\tau^{n}(i)$ maximizes $w_{i}+w_{0}$ by definition, it must be that $\Omega(i) \geq 0$. As this is true for any exporter, including the largest one, we conclude that the minimum implementable tariff is at least as low as the negotiated tariff for the set composed of the importer and the largest exporter.

Second, is it possible to implement the world efficient tariff $\tau^{w}$ ? That is, can the WTO induce full participation? We can answer this question with reference to the HHI of exporter concentration, defined as $H \equiv \sum_{i \in N} \theta_{i}^{2}$. 
Proposition 1. $\tau^{w}$ can be implemented if the Herfindahl-Hirschman index of exporter concentration $(H)$ is sufficiently high and cannot be implemented if $H$ is too low. Proof in Appendix A.

Full participation can occur only when the total willingness to pay of all exporters exceeds the importing country's opportunity cost. As each exporter's willingness to pay is related to its squared market share, total willingness to pay depends on $H$. Note that $H$ can take on values anywhere from 1 (the largest exporter controls the entire market) to $1 / N$ (each exporter has equal market share), and with large $N$, it can be close to zero. If $H=1$, we have already seen that participation of the largest exporter is an equilibrium, so $\tau^{w}$ can be implemented. If $H$ is close to zero, total willingness to pay is near zero, and thus $\tau^{w}$ cannot be implemented.

\subsection{Optimal mechanisms and the principal supplier rule}

While implementability alone may narrow the set of possible outcomes from multilateral negotiations, it does not produce a unique prediction. For this we need to be more specific about what the negotiations are designed to achieve. Suppose the WTO's objective is to maximize the joint welfare of its members, subject to $V$ and $P$, or equivalently to minimize $\tau^{n}(A)$, subject to $\Omega(A) \geq 0$. We know from Proposition 1 that full participation $(A=N)$ solves this problem, if $H$ is sufficiently high. Otherwise, the problem is more difficult: because the domain is discrete, it is a potentially intractable nonlinear integer programming problem. In this section, we show that this problem can be simplified considerably, with minimal loss of generality, by restricting attention to sets of participants obeying the principal supplier rule, defined as follows:

Definition. A set of participants $A$ obeys the principal supplier rule (PSR), if and only if there exists a critical exporter $x \in A$ such that $\theta_{i} \geq \theta_{x}$ for all $i \in A$, and $\theta_{i} \leq \theta_{x}$ for all $i \notin A$.

In other words, under the principal supplier rule, only the exporters above a certain size participate. As each PSR set is defined by a critical exporter $x$, we can then define functions $\Theta(x), \tau^{n}(x)$ and $\Omega(x)$ accordingly, ${ }^{15}$ noting that $\Theta(x)$ is monotonically increasing in $x$, while $\tau^{n}(x)$ is monotonically decreasing.

The virtue of the principal supplier rule can be seen by comparing any non-PSR set $A$ with a PSR set that is equivalent in the sense that $\Theta(x)=\Theta_{A}$. Because they have the same cumulative market share, these two sets produce the same negotiated tariff. However, it can be shown that $\Omega(x) \geq \Omega(A)$, meaning the PSR set must satisfy voluntary participation if $A$ does (and may do so even if $A$ does not). This is established formally in the proof, but the intuition is that total willingness to pay is an increasing function of the sum of the squared market shares of participants. For any given cumulative market share, the sum of the squared market shares is maximized by choosing the largest exporters. That is, a small group of large exporters has a greater total willingness to pay than a large group of small exporters (even though they have the same cumulative market share). What if $A$ has no equivalent PSR set? In that case, we can always find a PSR set $x$ such that $\Theta(x)<\Theta_{A}<\Theta(x+1)$ and $\Omega(x) \geq \Omega(A)$. Thus, there is at most a small loss of generality from focusing exclusively on PSR sets.

To state it more formally, we will say a tariff $\tau$ is feasible under PSR, if there exists $x \in N$ such that $\tau^{n}(x)=\tau$, and a tariff $\tau$ is implementable under PSR, if there exists $x \in N$ such that $\tau^{n}(x)=\tau$ and $\Omega(x) \geq 0$. We can now state a precise relationship between optimal mechanisms and the principal supplier rule.

Proposition 2. Let $\tilde{\tau}$ be the tariff implemented by the optimal mechanism, and let $\hat{\tau} \equiv \tau^{\mathrm{n}}(\hat{x})$ be the smallest tariff implementable under PSR.

\footnotetext{
15 Specifically, $\Theta(x) \equiv \sum_{i=1}^{x} \theta_{i}, \tau^{n}(x) \equiv \tau^{n}[\Theta(x)]$, and $\Omega(x) \equiv \sum_{i=1}^{x} w_{i}\left[\tau^{n}(x)\right]-w_{i}\left[\tau^{n}\left(\Theta(x)-\theta_{i}\right)\right]-$ $\left\{w_{0}(\bar{\tau})-w_{0}\left[\tau^{n}(x)\right]\right\}$.
}

If $\tilde{\tau}$ is feasible under PSR, then $\tilde{\tau}=\tau^{\mathrm{n}}$. Otherwise, $\tilde{\tau} \in\left(\tau^{\mathrm{n}}(\hat{x}+1), \hat{\tau}\right]$, and $\tilde{\tau} \rightarrow \hat{\tau}$ as $\theta_{\hat{x}+1} \rightarrow 0$. Proof in Appendix A.

Proposition 2 states that the smallest tariff implementable under PSR is either optimal or nearly so, and it establishes an upper bound on the error. The smaller is the market share of the largest nonparticipant the smaller the error. In the limit the error is zero.

There are three reasons to appreciate Proposition 2. First, it greatly simplifies the search for optimal mechanisms. To find the largest $x$ satisfying $\Omega(x) \geq 0$, one simply adds countries to the set of participants in rank order until the constraint binds. To go the extra mile of finding $\tilde{\tau}$, one need only search for sets with negotiated tariffs between $\tau^{n}(\hat{x})$ and $\tau^{n}(\hat{x}+1)$ and check if they satisfy $\Omega \geq 0$. Second, as we shall see in the next section, the simplicity afforded by focusing on PSR sets allows us to obtain comparative statics on $\hat{\tau}$. Proposition 2 tells us that results concerning $\hat{\tau}$ should carry over to $\tilde{\tau}$ with only a small amount of potential error. We rely on this fact for our empirical estimation. Finally, as a theoretical result on its own, the optimality (or nearoptimality) of PSR sets helps to rationalize the principal supplier rule itself. A protocol under which negotiations take place on a given product only if the principal suppliers participate is actually part of an optimal response to the MFN free rider problem. ${ }^{16}$

\subsection{The effect of exporter concentration with many exporters}

In this section, we explore the relationship between the optimal mechanism and the underlying distribution of market shares. To facilitate this, we assume a large number of exporters, each with relatively small market share, and in view of Proposition 2, we restrict attention to mechanisms satisfying the principal supplier rule. With small market shares, we can write the total willingness to pay by a PSR set of countries defined by $x$ as $h(x) \omega(x)$, where $h(x)=\Sigma_{i=1}^{x} \theta_{i}^{2}$ is the HHI of participants.

An outcome $(x, \tau)$ satisfying conditions $V, P$ and PSR solves the system,

$w_{0}^{\prime}(\tau)+\Theta(x) w^{* \prime}(\tau)=0$

$h(x) \omega(x) \geq \bar{w}_{0}-w_{0}(\tau)$

This is illustrated in Fig. 1. The curve $P$ shows the negotiated tariff for each $x$, as determined by Eq. (12). The shaded area above and including $V$ shows all values of $x$ and $\tau$ satisfying Eq. (13). Every outcome on the arc $O U$ can be implemented. The optimal mechanism implements point $O$, which is the outcome with the lowest tariff. ${ }^{17}$

Other things equal, an increase in the HHI of participants relaxes the voluntary participation constraint and lowers the negotiated tariff. This is because the participants' total willingness to pay (LHS of Eq. (13)) is proportional to $h(x)$. The empirical usefulness of this observation is limited, however, because we are not able to measure $h(x)$, without knowing the critical exporter $x$. This is endogenous and usually unobservable (to the econometrician). To get around this problem, we impose some structure on the distribution of market shares that will enable us to establish a connection between the HHI of participants $h(x)$ and the HHI of the whole market $H$. It turns out that if two distributions of market shares can be ranked according to first-order stochastic dominance (FSD), there is a tight connection indeed.

\footnotetext{
${ }^{16}$ Note that our principle supplier result does not depend on fixed costs of participation. Indeed, the inclusion of fixed costs in our model is neither necessary nor sufficient to generate the principal supplier rule and would require a number of additional, ad hoc assumptions. See Ludema and Mayda (2008a) for further discussion of this point.

17 If Eq. (13) holds with equality, the importer's payoff is $w_{0}(\bar{\tau})$, which represents no gain relative to the status quo. Each free rider gains by $\theta_{i}\left[w^{*}(\hat{\tau})-w^{*}(\bar{\tau})\right], i \notin A$, from improved market access. Each participating exporter gains by $\theta_{i}\left[w^{*}\left(\tau^{n}(\hat{x}-i)\right)-w^{*}(\bar{\tau})\right]$, $i \notin A$. Relative to market share, this is less than the gain to free riders, because participants must compensate the importer for its terms of trade loss.
} 


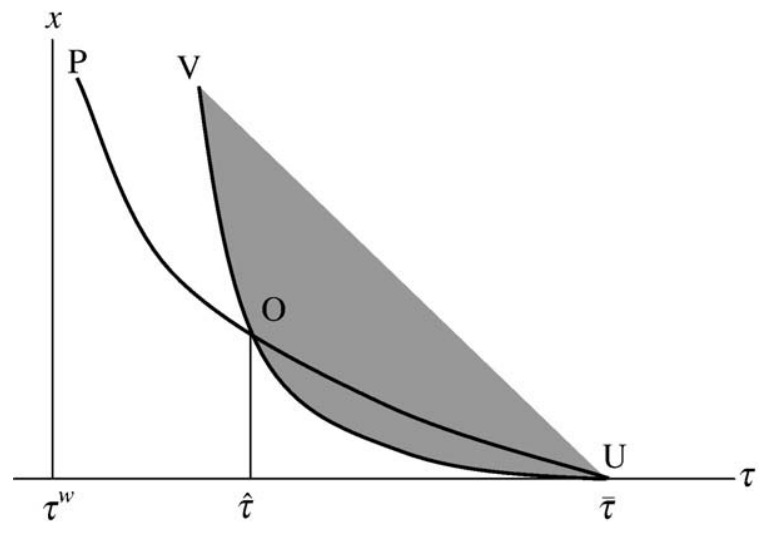

Fig. 1. All points along OU can be implemented. Point $O$ is optimal.

Proposition 3. Consider any two market share distributions such that $\Theta_{0}(x)<\Theta_{1}(x)$ for all $x$. If both distributions admit interior solutions, then the equilibrium market share of participants is higher, and the tariff lower, under $\Theta_{1}(x)$ than under $\Theta_{0}(x)$. Moreover, $H_{0}<H_{1}$, i.e., the overall market Herfindahl-Hirschman index is higher under $\Theta_{1}(x)$ than under $\Theta_{0}(x)$. Proof in Appendix A.

Thus, FSD is sufficient to ensure a negative, monotonic relationship between the overall $\mathrm{HHI}$ and the equilibrium negotiated tariff. This proposition is illustrated in Fig. 2. The $P$ schedule shifts to the left, because under the new distribution, the cumulative market share is higher for all $x$, and thus the negotiated tariff is lower for all $x$. The $V$ schedule shifts down because, for all $x$ the HHI of participants is now higher, meaning that the willingness-to-pay threshold for each $\tau$ is reached for a smaller $x$. The proof of the proposition shows that the shift in $V$ is greater than the shift in $P$, and thus the new equilibrium $O^{\prime}$ is left of $O$.

\subsection{Free trade agreements}

Before moving ahead to the empirics, there is one extension of the model that is necessary to make it applicable to a real-world setting: we need to account for preferential trade agreements. We do not consider the endogenous formation of PTAs, because we believe such decisions involve factors well outside the scope of this paper. For the most part, the introduction of exogenous PTAs requires little change in our model beyond reinterpretation. For example, if two or more of the exporters are members of a customs union (CU), we treat them as a single exporter, and if an exporter is part of a CU with the importer, we treat the pair as the importer. The interesting case is when the importer and an exporter (henceforth, the "partner") form a free trade area (FTA). In this case, the partner's incentives differ from those of the other exporters: the partner prefers a higher tariff to be imposed on the other exporters.

We assume that the partner does not participate directly in the negotiations but allow for the possibility that the importer takes into account the effect of its tariff on the partner. ${ }^{18}$ Also, to simplify, suppose $\lambda^{*}=0$. Thus, the objective of the importer is,

$$
\begin{aligned}
w_{0}+\phi w_{F T A}= & L_{0}\left[1+S(p)+\left(1+\lambda_{0}\right) \pi(p) k_{0}\right]+\left(p-p^{*}\right) E_{R}\left(p^{*}\right) \\
& +\phi L_{F T A}\left[1+S(p)+\pi(p) k_{F T A}\right]
\end{aligned}
$$

where $w_{F T A}$ is the welfare of the partner, $\phi$ measures the importer's concern for the partner, and $E_{R}$ denotes total exports of those

\footnotetext{
${ }^{18}$ This might be justified by assuming the importer and FTA partner engage in ongoing bilateral negotiations over non-trade policies, as in Limão (2007), so to increases in the importer's external tariff are partially extracted by the importer through negotiations, with $\phi$ reflecting the importer's bargaining share. This would suggest that $\phi$ lies between 0 and 1 . However, if the external tariff also affects the threat point of the negotiations, as is assumed by Limão, then $\phi$ could in effect exceed 1. Empirical evidence presented in Limão (2006) is consistent with this.
}

countries that are not members of the FTA. This gives rise to a modified negotiated tariff of,

$\tau^{n}(A)=\frac{1+\frac{1}{\xi_{R}}\left(1-\Theta_{A R}\right)}{1-\frac{1}{\mu+\xi_{F T A} \Theta_{F T A}}\left(\lambda_{0} \frac{X_{0}}{M_{0}}-(1-\phi) \Theta_{F T A}\right)}$

where $\Theta_{F T A}$ refers to the partner's share of the total home imports, and $\Theta_{A R}$ refers to the market share of non-FTA participants as a fraction of $E_{R}$. All of our previous results concerning the effects of concentration on the tariff are unchanged; however, here they apply to the HHI of non-FTA countries only. Moreover, note that the tariff is increasing in $\phi$ and decreasing in the partner's market share, for $\phi<1$.

\section{Empirical strategy and results}

In this section we empirically analyze the impact of MFN-related free riding on MFN tariff rates. Our analysis focuses on the United States and is based on two main data sets: the first one is a panel covering the years from 1989 to 1999; the second data set only includes information for the year 1983, but on a greater number of variables than the first one. Both data sets include MFN tariff rates, trade and production levels by sector.

Here is our plan of attack. We begin with a preliminary examination of the data, which reveals evidence broadly consistent with the predictions of the model: sector concentration, as measured by the Herfindahl-Hirschman index of export market shares, is indeed negatively and significantly correlated with U.S. MFN tariff rates in every year for which we have data. However, these are only correlations. We next worry about identification issues, which we address using an empirical specification that is closely related to the theoretical model and that takes into account institutional details, such as the timing of negotiations. Details of our specification will be provided later in this section. For now we give an outline of our identification strategy and timing of the analysis:

- We derive an estimating equation from the model to capture all of the covariates stressed in the theory, most notably, the HHI, domestic political-economy factors and the share of U.S. imports coming from FTA partners. Additional controls are added to account for non-GATT market share and foreign bargaining power.

- Using our panel, we examine the effect of 1993 covariates on average applied MFN tariffs from 1995 to 1999. The logic is that 1993 was the final and most critical year of the Uruguay Round negotiations, while 1995 to 1999 was the implementation period for the resulting tariff cuts. For our 1983 analysis this is not possible, since we only have data for a single year.

- To account for domestic political economy factors in the 1990s analysis, we include the inverse import penetration ratio and allow

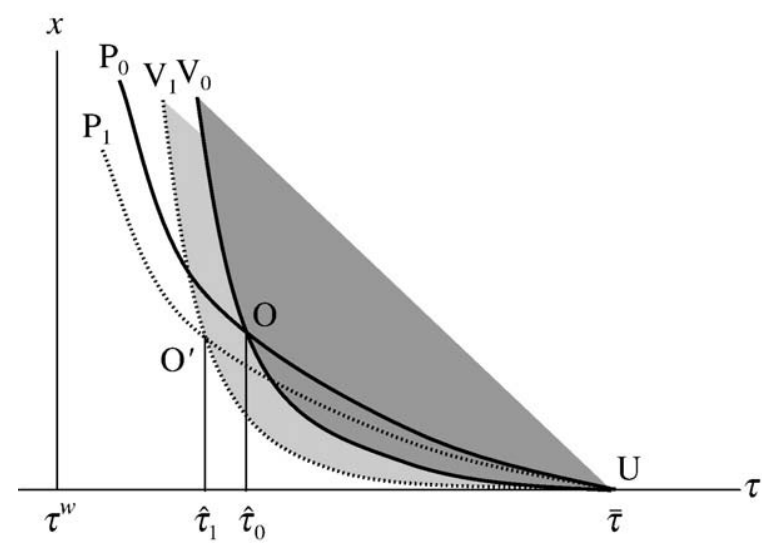

Fig. 2. The effect of an increase in concentration, under FSD. 
its coefficient to vary by industry. ${ }^{19}$ In the 1983 analysis, we go a step further, using data on political organization and import elasticities that has been widely used to test the "Protection for Sale" model.

- In the 1990s analysis, we instrument for the U.S. HHI using the Canadian HHI and another instrument based on the gravity model. In the 1983 analysis, we instrument for import penetration and political organization.

- For 1983 we estimate the effect of our covariates on tariffs and nontariff barriers (NTBs). The logic is that tariffs and NTBs share many common determinants but not the MFN free rider problem. Thus, if the HHI negatively affects NTBs, as it does tariffs, it would call into question whether $\mathrm{HHI}$ is really capturing the MFN free rider effect. Estimating the model with NTBs allows us to test whether omitted common determinants correlated with $\mathrm{HHI}$ are driving our tariff results.

- We estimate all specifications in levels, because our theory is static. However, we obtain similar results when considering differences between rounds.

To apply the theoretical model to the data, we assume that the tariff on each product $j$ is the outcome of an independent negotiation. This is true if the utility function is additively separable, implying independence across negotiated tariffs, and countries make their participation decisions on a product-by-product basis. A second assumption is $\lambda^{*}=0$, i.e., exporting governments care only about welfare. $^{20}$ Given that the U.S. has FTA partners during the sample period, the relevant equation for the negotiated tariff is Eq. (14). This equals 1 (free trade) if there is full participation, no domestic political pressure and negligible FTA share. Taking a first-order Taylor approximation of Eq. (14) around this point, and adding an error term, we obtain the following estimating equation:

$\tau_{j}-1=\frac{1}{\xi_{j}^{*}}\left(1-\Theta_{A R, j}\right)+\frac{\lambda_{j}}{\mu_{j}} \frac{X_{j}}{M_{j}}-\frac{1-\phi}{\mu_{j}} \Theta_{F T A, j}+\varepsilon_{j}$.

The variables we directly observe in the data are, $\tau_{j}-1, X_{j} / M_{j}$, and $\Theta_{\text {FTA, }}$, which measure, respectively, the MFN tariff rate, the inverse import-penetration ratio, and imports from FTA partners as a share of total imports, in sector $j$. The 1983 dataset also contains estimates of the elasticity of import demand ${ }^{21} \mu_{j}$ and political variables related to the parameter $\lambda_{j}$. We lack data on all other variables and thus treat them as parameters to be estimated. ${ }^{22}$

To estimate the MFN free-rider effect, the key variable in Eq. (15) is $\Theta_{A R, j}$, which measures U.S. imports from participants in GATT/WTO negotiations with the U.S. over product $j$ as a fraction of U.S. imports from all countries that are entitled to MFN treatment and are not U.S. FTA partners. Although we know the market share of each exporting country, we do not observe which countries participate in the negotiations over which good. Dealing with this problem was the ultimate purpose of Propositions 1 and 3. They tell us that we should focus on $H$, the $\mathrm{HHI}$ for the entire market. Proposition 1 says that $\Theta_{A R, j}$

\footnotetext{
19 Industries are defined at a higher level of aggregation (3-digit codes) than sectors (4-digit codes). We use the terms sectors, products and goods interchangeably throughout this section: they all refer to 4-digit codes.

${ }^{20}$ While we assume away foreign political pressure to derive our main equation, we address its potential effect later on in the 1983 NTB analysis.

${ }^{21}$ Note that the import demand elasticity $\mu_{j}$ appears in Eq. (15) instead of the FTAaugmented elasticity found in Eq. (14). This is because our approximation occurs around the point of zero FTA share, where the two elasticities are the same.

${ }^{22}$ Lacking data on export supply elasticities, we estimate a common coefficient on the HHI across sectors. This is tantamount to assuming common export supply elasticities across sectors, which is reasonable given that the U.S. probably has market power in almost all sectors. Ludema and Mayda (2008b) use several proxies for the inverse export supply elasticity at the sector level for more than 30 countries including the United States and find results consistent with what we show here. Broda et al (2008) estimate export elasticities for non-WTO countries and find that they influence tariffs in a way consistent with optimal tariff theory.
}

$<1$ if $H$ is low enough, and $\Theta_{A R, j}=1$ if it is high enough. Moreover, if the conditions of Proposition 3 are met, $\Theta_{A R, j}$ is a monotonically increasing function of $H^{23}$

Thus, the main prediction of the model is that, controlling for domestic political-economy determinants and FTA market share, the MFN tariff rate is negatively affected by the HHI. In our calculation of the HHI, we must account for the presence of non-GATT countries that receive MFN treatment and exclude U.S. FTA partners and other countries that do not receive MFN treatment. We measure this as,

$H_{j}=\frac{\sum_{i \in G A T T} M_{i j}^{2}}{\left(\sum_{i \in M F N} M_{i j}\right)^{2}}$

where MFN is the set of all non-FTA countries that export product $j$ to the U.S. and are granted MFN treatment by the U.S., while GATT is the subset of MFN consisting of members of the GATT/WTO (and are therefore potential participants in the multilateral negotiations). ${ }^{24} M_{i j}$ is the value of U.S. imports of product $j$ from country $i$. The HHI so defined equals the sum of squared export shares to the U.S. over all potential (non-FTA) participants. For our purposes the EC is considered a single country; however, our results are robust to including the member states individually. ${ }^{25}$

Given that our model is a story about multilateral trade negotiations, there are certain features of actual negotiations that should be respected. For one, GATT rounds take time, both to negotiate and implement. The Uruguay Round was negotiated between 1986 and 1994; the resulting tariffs were implemented in stages from 1995 to 1999. The tariffs in effect during the Round were primarily those negotiated during the Tokyo Round (1973-79). This suggests that covariates observed during a Round should impact tariffs during the implementation period. In light of this, we focus on the end of the Uruguay round and estimate the impact of the Herfindahl-Hirschman index in 1993 on the average MFN tariff rate over the following years (1995-1999). ${ }^{26}$ For our 1983 analysis this is not possible, since we only have data for a single year.

A second feature of GATT negotiations is that countries negotiate tariff bindings. That is, they do not explicitly agree to tariff levels but instead to tariff ceilings that tariff levels must not exceed. Thus, it might seem natural to focus on bound tariffs as our dependant variable. However, another important institutional feature is that applied $\operatorname{tariffs}^{27}$ are not immediately subject to the bound rates negotiated in a Round but are phased-in in stages, with more politically sensitive products phased-in as late as possible. This feature would be lost if we used only final bound rates. Moreover, although our theoretical model makes no distinction between the bound and

\footnotetext{
${ }^{23}$ Although the export share distributions in the data cannot be strictly ranked according to FSD, most of the deviations from FSD we find are quite small. Our empirical results do not change (if anything they are strengthened) when we exclude outlying sectors, where an outlier is defined as a sector that is rejected by the SchmidTrede (1996) test of FSD at the 10\% level (the test compares each sector with the sectors above or below it in the HHI ranking). We should emphasize that FSD is only a sufficient condition for monotonicity, not a necessary one.

${ }^{24}$ While Eq. (16) conforms to the theoretical model, our results are robust to constructing $H_{j}$ using either $i \in M F N$ in the numerator or using $i \in G A T T$ in denominator

${ }^{25}$ In 1983, the EC consisted of Belgium, Luxembourg, Netherlands, Germany, France, Italy, Denmark, Ireland, United Kingdom, Cyprus, and Greece. By 1993, Portugal and Spain had joined (Austria, Finland, and Sweden joined in 1995; Turkey joined the customs union in 1996). Interestingly, the coefficient estimates on $\mathrm{HHI}$ in regressions where European countries are considered separately are larger in absolute value.

${ }^{26}$ It might be reasonable to use the average of the HHI from 1989-1993, rather than the $1993 \mathrm{HHI}$. We prefer the $1993 \mathrm{HHI}$ on the grounds that 1993 captures the most recent information that negotiators had during the final and most critical part of the negotiation. As a robustness check we have estimated the model using 1989-1993 averages and found very similar results (Ludema and Mayda, 2008a, Table B).

27 The term "applied" rate is used quite loosely in the literature and is computed in various ways. Here we mean the MFN ad valorem tariff rate actually found in the US harmonized tariff schedule in a given year.
} 
applied rates, Bagwell and Staiger (2005) provide a theory to account for the difference, based on private information about political pressure. In their model, the bound rate is chosen to ensure the incentive compatibility of applied rates, whereas applied rates maximize the expected welfare of the negotiating parties. Accordingly, the applied rate is the more appropriate measure of our negotiated tariff. In practice, the difference between the two sets of tariff rates in the U.S. data is quite small (Ludema and Mayda, 2008a, Figures A and B). When we estimate our 1993 model using final bound rates, as a robustness check, we find nearly identical results (Ludema and Mayda, 2008a, Table A).

Previous literature on endogenous protection has emphasized domestic political-economy factors. Although the details are not of particular interest to our theory, we need to control for these factors, as they might be correlated with sector concentration and give rise to an omitted variable bias. Using the first data set, we account for domestic political-economy factors indirectly, by controlling for the inverse importpenetration ratio and allowing its coefficient to vary by industry. This amounts to assuming that $\lambda_{j} / \mu_{j}$ in Eq. (15) varies by industry. When we use the second data set, which focuses on a single year (1983), we have access to a larger number of variables. In particular, we have data on political contributions by sector, which previous literature (Goldberg and Maggi, 1999; Gawande and Bandyopadhyay, 2000) has used as a proxy for $I_{L j}$, the latter being the variable component of the Grossman and Helpman (1994) term, $\lambda_{j}=\left(I_{L j}-\alpha_{L}\right) /\left(a+\alpha_{L}\right)$. Our purpose here is not to contribute anything new to this literature. Rather, we use the same specification and data set as these previous papers to show that our results are consistent with them.

\subsection{Results from the Uruguay Round}

We use the World Bank's Trade and Production Database (Nicita and Olarreaga 2001), which includes data on applied MFN tariffs, multilateral and bilateral trade flows and production for 75 manufacturing industries at the 4-digit level of the International Standard Industrial Classification (ISIC Rev. 2). ${ }^{28,29}$ Data is available for the years 1989 to 1999 (excluding 1994). We obtain information on GATT/WTO membership from Rose (2004) and on MFN treatment from the U.S. Harmonized Tariff Schedule. ${ }^{30}$

From 1993 to 1999 the average U.S. MFN tariff rate decreased by about 1.75 percentage points. ${ }^{31}$ There is a negative and significant correlation between the MFN tariff rate and the HHI for each of those years. However, for each of the years between 1995 and 1999, when we regress the tariff on the contemporaneous HHI and the $1993 \mathrm{HHI}$ together, we find a negative and significant coefficient on the latter variable and an insignificant coefficient on the former (results not shown). This suggests that the tariffs of the Uruguay Round implementation period are indeed driven by the HHI during the negotiations.

Regression (1) in Table 1 shows the estimated effect of the $1993 \mathrm{HHI}$ on the average tariff (1995-99) when no other controls are included in

\footnotetext{
28 This dataset derives from several sources: the UNCTAD Trains, UN Comtrade, and UNIDO Industrial Statistics databases are the sources of MFN tariffs, trade flows and production data, respectively. Tariffs are MFN simple averages at the 4-digit level of the ISIC classification.

29 The advantage of the World Bank data set is that it provides data across countries according to the same international classification - which we use to construct instruments for the U.S. HHI. The disadvantage is that the level of disaggregation is not very high. Additional results based on data classified according to the 4-digit U.S. SIC classification and the 8-digit Harmonized System classification are, respectively, presented and discussed at the end of this section.

${ }^{30}$ From 1996 onwards, the only non-MFN countries were Afghanistan, Cuba, Laos, North Korea, Iran, Vietnam, Serbia and Montenegro. Before then, the US granted unconditional MFN to all other countries, except Communist countries. Communist countries began receiving MFN treatment in the nineties.

${ }^{31}$ In addition to the transition from one set of bound rates to another, during the Uruguay Round phase-in period (1995-1999), time variation in applied rates may be due to discretionary changes in applied tariffs that are below bound rates. Countries also exercise some discretion in whether tariff reductions negotiated in a round are implemented on schedule. Finally, another source of tariff changes are renegotiations that occur between rounds, as allowed by Article XXVIII.
}

the regression. ${ }^{32}$ Columns (2)-(5) show the estimates of Eq. (15), introducing domestic political-economy determinants and the FTA market share. In particular, we employ industry dummy variables to proxy for $\lambda_{\mathrm{j}} / \mu_{j}$ and include the import share of FTA countries, Israel and Canada. ${ }^{33}$ Thus, our main specification (regression (2), Table 1) looks as follows:

$\tau_{95-99, j}-1=\alpha+\beta \cdot H_{93, j}+\sum_{l} \eta_{l} \cdot I_{l} \frac{X_{93, j}}{M_{93, j}}+v \cdot \Theta_{F T A 93, j}+\varepsilon_{j}$.

where $\tau_{95-99, j}-1$ is the average ad-valorem U.S. MFN tariff rate over the years 1995-1999, $X_{93, j} / M_{93, j}$ is the inverse import-penetration ratio in 1993 (ratio of domestic total output to imports), $\Theta_{\mathrm{FTA}}$ 93, is FTA countries' share of U.S. imports in 1993, $j$ is the 4-digit ISIC code and $l$ is the 3-digit ISIC code.

With or without controls, the correlation between the U.S. MFN tariff rate and the HHI is negative and significant at the $1 \%$ level (regressions (1) and (2), Table 1). The estimate is even higher when the controls are included. According to column (2), a 10 percentage points increase in the HHI decreases the MFN tariff rate by 0.8 percentage points (which represents a $20 \%$ decrease given that the mean of the dependent variable is equal to 4.2 percentage points in regression (2)).

Another way to gauge the magnitude of this effect is to compare actual tariffs to the counterfactual of no free riding. In Ludema and Mayda (2008a), we calibrate a model, assuming linear demand and Leontief production, and find that full participation obtains for $\mathrm{HHI}$ greater than about 0.42 . We then ask how much tariffs would decline on average if all $1993 \mathrm{HHI}$ 's were raised to this level. Using the point estimates in column (2), we find an average percentage difference of $33 \%$, i.e. absent free riding due to the MFN clause tariff rates would be two thirds of their current levels. ${ }^{34}$

According to the theoretical model, the FTA market share has a negative effect on the MFN tariff rate if $\phi<1$. The intuition behind this is that, the larger the export market share of FTA partners, the smaller the terms-of-trade gain for the U.S. from setting a high tariff (as the price of goods coming from FTA partners equals the domestic price) and, therefore, the lower the MFN tariff rate. We find evidence consistent with this in regression (2) where the coefficient on the FTA share variable is estimated to be negative and significant (at the $10 \%$ level). Notice that, while the FTA share variable could be endogenous due to reverse causality, this is likely to bias the estimate of the coefficient towards zero, as higher MFN tariff rates should increase import shares from FTA partner countries.

The remaining specifications in Table 1 further test the robustness of our findings. First, our theory assumes that exporting countries reciprocate with transfers, while in practice countries exchange trade barrier concessions of various kinds. In such a world, it could be that the U.S. is more inclined to swap concessions with countries that represent a large market for U.S. exports (e.g., EC). One might be concerned that the goods principally supplied by such countries have high $H_{j}$, thus causing a negative correlation between $H_{j}$ and $\tau_{j}$ unrelated to MFN. To address this issue, in column (3) we control for the share of U.S. total exports (i.e., of all goods) to the top five exporters to the U.S. of each product. This variable represents a measure of U.S. overall export dependence on the principal suppliers of each good the U.S. imports. ${ }^{35}$

\footnotetext{
${ }^{32}$ All our regressions use robust standard errors to address heteroskedasticity. Outliers (observations with tariffs higher than 50) are excluded from the analysis in Table 1.

${ }^{33}$ We use the definition of Article XXIV to determine FTA status. Countries that may have received preferential treatment through other means, such as the Generalized System of Preferences, are treated as MFN non-FTA countries. We take this approach mainly because of the inconsistent coverage and conditional nature of these preferences.

${ }^{34}$ The $33 \%$ average percentage tariff difference caused by free riding is a conservative estimate, for reasons described in Ludema and Mayda (2008a).

${ }^{35}$ Bown (2004) uses essentially the same measure. He finds that the greater a country's export dependence on the principal suppliers of a given product, as measured by the share of its worldwide exports (of all products) sold to those suppliers, the less likely it is to implement protection (safeguards and safeguard-like measures) on that product.
} 
Table 1

The impact of free-riding on US MFN tariff rates, using 4-digit ISIC and SIC data (1993-1999)

\begin{tabular}{|c|c|c|c|c|c|c|c|c|}
\hline \multirow{3}{*}{ Dependent variable } & 1 & 2 & 3 & 4 & 5 & 6 & 7 & 8 \\
\hline & \multicolumn{8}{|c|}{ Average US MFN tariff rate (1995-1999) } \\
\hline & \multicolumn{5}{|c|}{ 4-digit ISIC } & \multicolumn{3}{|c|}{ 4-digit SIC } \\
\hline Method & $\overline{\mathrm{OLS}}$ & OLS & OLS & IV & IV & $\overline{\mathrm{OLS}}$ & OLS & OLS \\
\hline \multirow[t]{2}{*}{ Herfindahl-Hirschman index (1993) } & -6.15 & -7.78 & -11.04 & -6.77 & -7.24 & -5.98 & -3.72 & -3.03 \\
\hline & $2.07 * *$ & $2.73 * *$ & $3.36^{* *}$ & $3.66+$ & $3.87+$ & $1.14^{* *}$ & $1.37 * *$ & $1.51^{*}$ \\
\hline \multirow[t]{2}{*}{ FTA share (1993) } & & -4.5 & -6.65 & -4.46 & -4.48 & & -4.43 & -4.25 \\
\hline & & $2.62+$ & $3.38+$ & $2.62+$ & $2.62+$ & & $1.08^{* *}$ & $1.13^{* *}$ \\
\hline \multirow[t]{2}{*}{ Share of US exports to top 5 exporters (1993) } & & & -0.12 & & & & & -11.05 \\
\hline & & & 6.29 & & & & & $3.59 * *$ \\
\hline \multirow[t]{2}{*}{ Non-GATT market share (1993) } & & & -5.85 & & & & & -0.84 \\
\hline & & & 4.19 & & & & & 2.15 \\
\hline \multirow[t]{2}{*}{ Constant } & 5.59 & 6.62 & 8.63 & 6.41 & 6.51 & 6.23 & 6.56 & 10.4 \\
\hline & $0.61 * *$ & $1.15^{* *}$ & $2.80 * *$ & $1.26 * *$ & $1.31^{* *}$ & $0.40 * *$ & $0.65 * *$ & $1.63 * *$ \\
\hline Inverse import penetration ratio (1993)*3-digit DV & No & Yes & Yes & Yes & Yes & No & Yes & Yes \\
\hline Observations & 75 & 75 & 75 & 75 & 75 & 386 & 386 & 386 \\
\hline R-squared & 0.1 & 0.59 & 0.62 & 0.59 & 0.59 & 0.08 & 0.63 & 0.67 \\
\hline
\end{tabular}

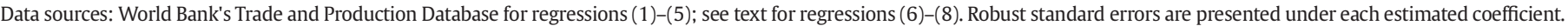
+ significant at $10 \%{ }^{*}$ significant at $5 \%$; $* *$ significant at $1 \%$. Outliers, that is US MFN tariff rates higher than 50 , are dropped. The US MFN tariff rate is expressed in percentage points.

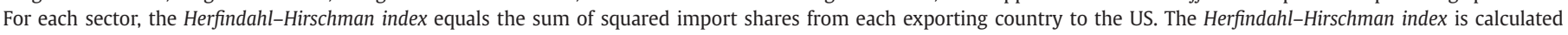

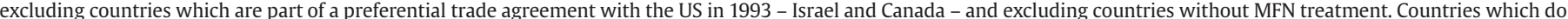

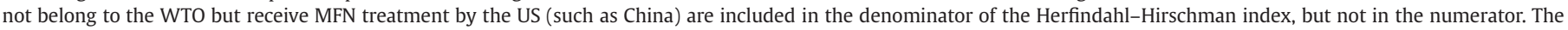

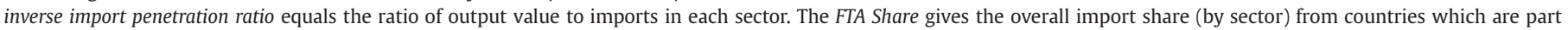
of a preferential trade agreement with the US (Israel and Canada).

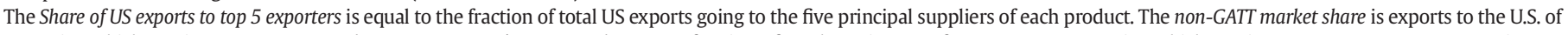

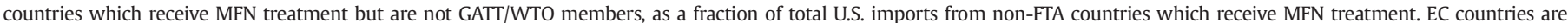

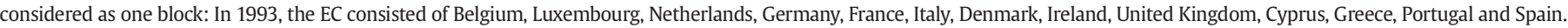

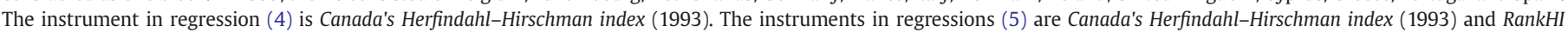

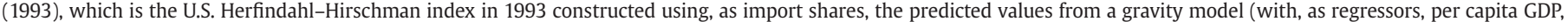
population, distance and the rank of each country in world exports of each product).

Second, our theory focuses on the participation decisions of GATT WTO countries. Non-GATT countries receiving MFN (e.g., China) are included in the denominator of $H_{93, j}$, because they enjoy the MFN externality (the terms-of-trade improvement from a reduction in the U.S. tariff) but are excluded from the numerator, because they are not potential participants. Therefore, the higher the non-GATT market share the lower our measure of the HHI. In regression (3) we add the non-GATT market share as a control to make sure that it does not drive the estimate on the HHI. ${ }^{36}$ The two additional regressors in column (3) (Share of US exports to top 5 exporters and non-GATT market share) turn out to have no effect on the negative and significant coefficient on the $\mathrm{HHI}$, if anything the coefficient becomes larger in absolute value.

Third, up to now we have addressed the potential endogeneity of the HHI by strictly following the theoretical model and controlling for the other determinants of tariffs in Eq. (15). However, it is possible that other domestic political-economy determinants of U.S. MFN tariff rates, not captured in the theoretical model, are correlated with the HHI. To deal with this possibility, we estimate the model using Canada's HHI as an instrument for the U.S. HHI (regression (4)): Canada's exporter concentration is correlated with that of the U.S. ${ }^{37}$ but is unlikely to be correlated with U.S.-specific political-economy dynamics. Another concern is reverse causality: a higher tariff rate may affect the exporting countries' market shares and thereby influence the HHI. This cannot occur in our theoretical model, which assumed export market shares independent of the world price, but it might be true in the data if the elasticities of export supply differ across countries. Even then, for differences in elasticities to explain the negative relationship between the tariff and the HHI, they would have to vary by market share systematically: countries with larger market share would have to reduce exports in response to higher tariffs proportionally more than do countries with smaller market share. To

\footnotetext{
${ }^{36}$ The bias induced by the non-GATT market share could go either way, according to whether bilateral negotiations take place between the U.S. and non-GATT MFN countries.

37 The correlation coefficient between the U.S. HHI and the Canadian one is 0.81 .
}

address this possibility, we instrument the U.S. HHI with the variable RankHI: this variable is equal to the U.S. HHI constructed using, as import shares, the predicted values from a gravity model with, as regressors, per capita GDP, population, distance and the rank of each country in world exports of each product (regression (5)). The implicit assumption is that country ranks in world exports are not systematically affected by U.S. tariffs. The results from instrumental-variable regressions seem to confirm our previous results on the effect of exporter concentration. ${ }^{38,39}$

Finally, one of the limitations of the World Bank data set is its relatively high level of aggregation - only 75 observations at the 4digit level of ISIC. We next check the robustness of our results to using more disaggregated data, specifically at the 4-digit SIC (1987) level (386 observations) and at the 8-digit Harmonized System level (7670 observations) ${ }^{40}$ Regressions (6)-(8) of Table 1 show the results of using the 4-digit SIC (1987) product classification, which is the least aggregated classification for which U.S. production data is available. The results confirm all of our previous estimates. The main difference with the results using the World Bank data is that the coefficient estimates on FTA Share and Share of US exports to top 5 exporters are now negative (as expected) and significant at the $1 \%$ level (most likely, the significance level increases as the data is more disaggregated).

In actual GATT negotiations, the items under negotiation are legal tariff lines, which are defined at the 8-digit Harmonized System (HS) level for the US. Given the many thousands of items at this level,

\footnotetext{
38 Regression (5) uses both Canada's HHI and RankHI as instruments for the U.S. HHI (we confirm the validity of the instruments with a test of overidentifying restrictions). Based on both regressions (4) and (5), the Hausman test cannot reject the null hypothesis that the U.S. HHI is exogenous.

39 In Ludema and Mayda (2008a), we also estimate the model using a two-stage estimation procedure that allows us to account for both the ongoing effects of political pressure and the once-off effect of the Herfindahl-Hirschman index, between 1995 and 1999.

${ }^{40}$ Production data at the 4-digit SIC (1987) level are from Peter Schott's website. MFN tariff rates and import data at the 8-digit HS level are from, respectively, John Romalis'
} and Robert Feenstra's websites. 
however, it seems plausible that countries would economize on participation decisions and negotiate products in groups (perhaps 4 or 6 digit categories). Thus, we conduct the analysis at the 4-digit ISIC or 4-digit SIC level, which amounts to a between-group analysis. Yet if Pareto efficiency for participants applies at the tariff line level, then even if the set of participants varies only between groups, we may still see a negative relationship between $H$ and $\tau$ within groups, i.e. controlling for 4-digit or 6-digit fixed effects. ${ }^{41}$ In fact, we see this in the data. Although the results are not shown, we find a negative and significant relationship between the average U.S. MFN tariff rate (1995-1999) and the $1993 \mathrm{HHI}$ at the 8-digit HS level, which is robust to controlling for both 4-digit fixed effects and 6-digit fixed effects (which capture, among other effects, domestic political-economy determinants). Details are available upon request from the authors.

\subsection{Results from the Tokyo Round}

We next focus on 1983 for which we have information on a range of additional variables. ${ }^{42}$ Our purpose in using this dataset is not just to replicate the 1990s results but to go beyond them. In particular we use direct information on sectors' political organization status and import-demand elasticities (which were kindly provided by Gawande) to estimate the following model:

$\tau_{j}-1=\alpha+\beta \cdot H_{j}+\gamma \cdot \frac{1}{\mu_{j}} \cdot \frac{X_{j}}{M_{j}}+\delta \cdot I_{L j} \cdot \frac{1}{\mu_{j}} \cdot \frac{X_{j}}{M_{j}}+\varepsilon_{j}$,

where $\tau_{j}-1$ is the U.S. post-Tokyo round ad-valorem tariff and $I_{L j}$ is a political-organization dummy for sector $j$. Notice that, as in the previous literature, we break down the parameter $\lambda_{j}$ in formula (15) into two components, according to whether the sector is politically organized or not. ${ }^{43}$

Table 2 presents the estimates of this specification. Notice that we follow Goldberg and Maggi (1999) in treating the import demand elasticity as econometrically endogenous, thus we move it to the lefthand side of expression (18). We find that the data is consistent with this specification of the model and, in particular, that the impact of the HHI on the U.S. MFN tariff rate is still negative and significant once we account for "Protection for Sale" determinants (regressions (1) and (2)). ${ }^{44}$ Our results are robust to introducing the direct effect of Political Organization (regression (3)) and to using a different measure of political organization ${ }^{45}$ (regression (4)). We also confirm that the Share of US exports to top 5 exporters has a negative and significant impact and that its introduction does not affect the coefficient on the $\mathrm{HHI}$ (regression (5)).

Next, as in Goldberg and Maggi (1999), we treat the politicalorganization measure and the inverse import-penetration ratio as econometrically endogenous. We construct instruments for $I_{L j}$ and $X_{j} /$ $M_{j}$ using data kindly provided by Trefler. In particular, we model the inverse import-penetration ratio as in cross-commodity regressions of

\footnotetext{
41 As an example, consider two exporters, 1 and 2, and two tariff lines, A and B, with a single negotiation for both lines. If country 1 's export share is $80 \%$ for $A$ and $50 \%$ for $B$, then as the combined principle supplier, country 1 participates for sure, while country 2 may free ride. In that case, the resulting negotiated tariff would be higher for $\mathrm{B}$ (with $\mathrm{HHI}$ equal to 0.5 ) than for $\mathrm{A}$ (with $\mathrm{HHI}$ equal to 0.68 ).

42 The 1983 data follow the 4-digit U.S. Standard Industrial Classification (SIC, 1972based).

43 In other words, $\lambda_{j}=\gamma+\delta \cdot I_{L j}$, with $\gamma=-\alpha_{L} /\left(a+\alpha_{L}\right)<0, \delta=1 /\left(a+\alpha_{L}\right)>0$ and $\gamma+\delta>0$.

44 Regressions (1)-(2) provide information on the importance of free riding versus political-economy determinants. The difference between the two $R^{2}$ measures (equal to 0.08 ) is the variance of tariffs, left unexplained by the political-economy determinants, which is explained by free riding.

${ }^{45}$ In Table 2, we use two different measures of Political organization. GB Political Organization is the same variable used in Gawande and Bandyopadhyay (2000), who consider as politically-organized those sectors where import penetration (from major partners) significantly explains the size of political contributions. We construct GM Political Organization as in Goldberg and Maggi (1999), using information from their Table B1 (p.1153).
}

trade flows, i.e. as a function of sector factor shares. As instruments for the political-organization dummy, we use variables employed in the political-economy literature as determinants of endogenous protection (Trefler 1993). ${ }^{46}$ Both sets of instruments are used for both variables (their list can be found at the end of Table 2). Once again, we confirm our result that the HHI has a negative and significant impact on MFN tariff rates (regressions (6) and (7)).

As stressed earlier, endogeneity of export concentration is an issue in the estimation of the impact of free riding. ${ }^{47}$ In addition, endogeneity of the HHI per se is not the only problem. While our estimates may be indicative of a causal negative impact of exporters' concentration on MFN tariff rates, the channel through which the effect is working may not be free riding. For example, a higher concentration of exporters in the U.S. market of product $j$ may increase the incentive of those few foreign exporters to get organized and lobby directly the U.S. government or their own government (high $\lambda^{*}$ ) for lower protection. In that case, we would observe a lower tariff rate on that good, but it wouldn't be due to free riding. In order to investigate these issues, we next estimate a model of U.S. nontariff barriers (NTBs). We use the same regressors we used to analyze MFN tariff rates.

It is reasonable to assume that tariff rates and NTBs share many common determinants. That the two forms of protection are affected by the same domestic political-economy factors was established by Ray (1981) and can be seen by comparing our results with those of Goldberg and Maggi (1999) and Gawande and Bandyopadhyay (2000), which focus only on NTBs. Foreign lobbying also affects tariffs and NTBs in a similar manner, as shown by Gawande et al. (2006). One important difference is that, while in theory NTBs too are subject to the MFN clause (GATT Article I), in practice they constitute one of the most common departures from nondiscrimination. ${ }^{48}$ This implies that NTBs should not suffer from the MFN free rider problem. ${ }^{49}$ Thus, loosely speaking, NTBs represent a counterfactual of the level of protection of MFN tariff rates, absent the free-riding effect through the MFN clause. According to this argument, we would not expect a regression of NTBs on exporter concentration to yield the negative and significant result we found for tariffs.

Figs. 3 and 4 offer evidence consistent with this intuition. Using the 1983 data, the correlation between the HHI and the MFN tariff rate is negative (the regression coefficient of the fitted line in Fig. 3 is -8.95 , significant at the $1 \%$ level), while NTBs appear to be positively related

\footnotetext{
${ }^{46}$ Notice that, for the political-organization dummy, in the first stage we specify a linear reduced-form equation. On the other hand, Goldberg and Maggi (1999) use a probit model.

${ }^{47}$ However, some of the possible omitted variable biases reinforce our results. The $\mathrm{HHI}$ of export shares may be positively correlated with domestic (firm) concentration in the importing country, but this would tend to bias our estimate towards zero. The reason is that higher domestic firm concentration in the importing country could positively affect whether the sector is politically organized at home $(\lambda)$. In a similar vein, strategic trade policy considerations would suggest tariffs should be higher in sectors where firm concentration is high both at home and abroad. Again this reinforces our results. We thank Ralph Winter and Jim Brander for pointing this out. ${ }^{48}$ NTBs include anti-dumping duties, countervailing duties, country-specific quotas, VERs and a host of other discriminatory policies. Jackson notes: "Quantitative restrictions often pose an important conceptual challenge to the MFN principle.... In a similar context, the explosion of the use of export-restraint arrangements in world trade provided one of the most significant recent challenges [to MFN]." (1997, p. 164). ${ }^{49}$ NTBs can be set either cooperatively but in a discriminatory manner or noncooperatively. Either way, NTBs should not suffer from the MFN free rider problem. If we assume that all NTBs are noncooperative, then other aspects of multilateral negotiations (other than free riding) could, in principle, explain the exporter concentration effect for tariff concessions. However, first, the NTB test still allows us to rule out any omitted variable biases unrelated to multilateral negotiations (for example, the impact of foreign lobbying on the U.S. government). Second, the most notable aspect of multilateral negotiations, other than free riding, that could potentially explain the negative correlation between MFN tariff rates and the $\mathrm{HHI}$ is foreign bargaining power, which we have already accounted for in our analysis. Finally, and most importantly, it is not the case that all NTBs are noncooperative. Some NTBs, such as quotas, are set cooperatively, while even the least cooperative policies antidumping duties - have been shown to respond to foreign bargaining power (see Blonigen and Bown, 2003).
} 
Table 2

The impact of free-riding on US MFN tariff rates, using 4-digit SIC data (1983)

\begin{tabular}{|c|c|c|c|c|c|c|c|c|}
\hline \multirow[b]{2}{*}{ Dependent variable } & 1 & 2 & 3 & 4 & 5 & 6 & 7 & \multirow{2}{*}{$\frac{8}{(\text { US NTB) *elasticity }}$} \\
\hline & \multicolumn{7}{|c|}{ (US ad valorem tariff)*elasticity } & \\
\hline Method & $\overline{\text { OLS }}$ & OLS & OLS & OLS & OLS & IV & Tobit IV & IV \\
\hline \multirow{2}{*}{ Herfindahl-Hirschman index } & & -15.12 & -15.49 & -15.7 & -13.62 & -9.04 & -9.02 & 19.44 \\
\hline & & $2.82^{* *}$ & $2.83 * *$ & $2.82^{* *}$ & $2.54 * *$ & $2.05^{* *}$ & $2.38 * *$ & 19.16 \\
\hline \multirow[t]{2}{*}{ Inverse import penetration ratio } & -105.17 & -73.14 & -42.11 & -260.72 & -89.84 & -142.99 & -317.75 & -154.6 \\
\hline & $35.50 * *$ & $34.10 *$ & $22.89+$ & $81.92^{* *}$ & $27.88 * *$ & 117.8 & $120.61^{* *}$ & 373.52 \\
\hline \multirow[t]{2}{*}{ Inverse import penetration ratio*GB Political Organization } & 91.85 & 63.25 & 29.63 & & 79.88 & 126.35 & 296.38 & 63.36 \\
\hline & $35.13^{* *}$ & $34.01+$ & 23.33 & & $27.93 * *$ & 124.65 & $125.25^{*}$ & 418.54 \\
\hline \multirow[t]{2}{*}{ Inverse import penetration ratio*GM Political Organization } & & & & 248.93 & & & & \\
\hline & & & & $81.56^{* *}$ & & & & \\
\hline \multirow[t]{2}{*}{ GB Political Organization } & & & 2.77 & & & & & \\
\hline & & & $1.18^{*}$ & & & & & \\
\hline \multirow[t]{2}{*}{ Share of US exports to Top 5 Exporters } & & & & & -21.24 & & & \\
\hline & & & & & $7.16^{* *}$ & & & \\
\hline \multirow[t]{2}{*}{ Constant } & 10.28 & 14.2 & 12.36 & 14.45 & 23.72 & 11.45 & 11.65 & 10.89 \\
\hline & $0.67 * *$ & $1.17 * *$ & $1.11^{* *}$ & $1.18^{* *}$ & $3.83^{* *}$ & $0.96 * *$ & $0.80^{* *}$ & $5.38^{*}$ \\
\hline Observations & 242 & 242 & 242 & 242 & 242 & 194 & 194 & 194 \\
\hline R-squared & 0.02 & 0.1 & 0.11 & 0.11 & 0.15 & 0.06 & & \\
\hline
\end{tabular}

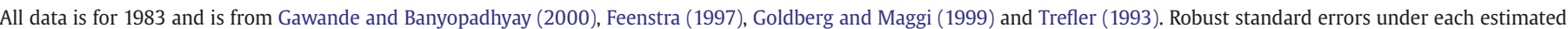
coefficient. + significant at $10 \%$; significant at $5 \%$; ** significant at $1 \%$.

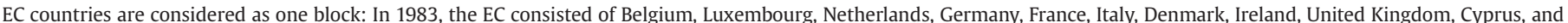
Greece. The US post-Tokyo round ad valorem tariff is expressed in percentage points.

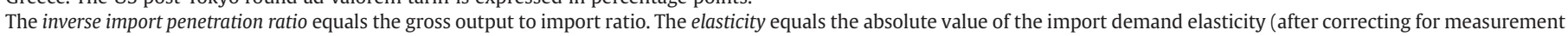

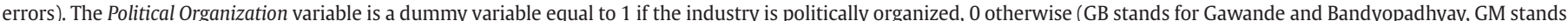

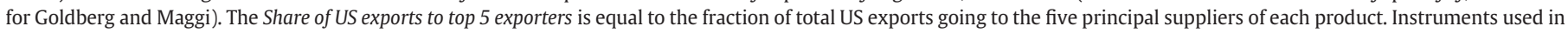

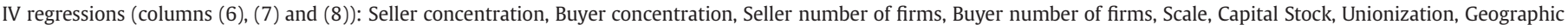
concentration, Tenure; Physical capital, Inventories, Engineers\&scientists, White-collar, Skilled, Semi-skilled, Unskilled, Cropland, Pasture, Forest, Coal, Petroleum, Minerals.

(although insignificantly) to exporter concentration (see Fig. 4). Column (8), Table 2 confirms this result using regression analysis (IV estimation). The impact of exporter concentration on NTBs is positive and insignificant, using the same instruments as in regressions (6) and (7) for the inverse import penetration ratio and the political organization dummy. ${ }^{50}$ The nonnegative effect of HHI on NTBs is robust to jointly estimating tariffs and NTBs with three-stage least squares and to including the tariff as an explanatory variable in the NTB equation. To conclude, we believe we found evidence that the negative relationship between the HHI and MFN tariff rates is indeed related to the effect of free riding.

Finally, there is one other omitted variable concern that is not addressed by our previous methods, because it is a function of the MFN free rider problem itself. It is that participants may try to constrain the MFN externality via reciprocity and that their determination to do so might be greater when MFN free-rider issues are more severe (i.e., $H$ is low). This would imply that when $H$ is low (and our model predicts that $\tau$ should be high), endogenous mitigation of the MFN externality should reduce the incentive for free riding, thereby lowering the tariff relative to our prediction. In other words, the presence of this effect should bias the coefficient on $H$ towards zero. The fact that we find a negative and significant coefficient on $H$ tells us that, whatever the importance of this effect, the MFN free rider problem persists to some degree.

\subsection{Changes across rounds}

Thus far we have dealt with endogeneity by adding controls, using instrumental variables and estimating the NTB equation. As a final robustness check, we control for time-invariant unobserved heterogeneity across sectors by examining changes in tariffs between the Tokyo and Uruguay rounds rather than levels. An important caveat is that tariffs are well known to exhibit persistence, as shown by Baldwin (1985) and as evidenced by the gradual nature of GATT tariff reductions

\footnotetext{
${ }^{50}$ As in previous literature, the estimated effect of domestic political-economy determinants on NTBs is consistent with the protection for sale model, though the significance level of the estimates depends on the particular specification used.
}

over the past 60 years. ${ }^{51}$ This suggests that tariff changes between rounds involve longer-term considerations beyond first differences in the explanatory variables emphasized in our static model. To illustrate, suppose that tariff changes are governed by a linear difference equation, $\tau_{t}-\tau_{t-1}=b\left(\tau_{t}^{n}-\tau_{t-1}\right)$, where $0<b<1$. That is, the actual tariff change between rounds is a fraction of the difference between the target $\tau_{t}^{n}$ (given by Eq. (17)) and the tariff of the previous round. Solving produces,

$\tau_{t}-\tau_{t-1}=b\left(\tau_{t}^{n}-\tau_{t-1}^{n}\right)+b(1-b)\left(\tau_{t-1}^{n}-\tau_{0}\right)-b^{2} \sum_{i=2}^{t}(1-b)^{i-1}\left(\tau_{t-i}^{n}-\tau_{0}\right)$

The first term on the right-hand side captures the effect of changes of our covariates (HHI, etc.) between rounds. The second term is the gap between the previous target and the initial tariff. If we assume $\tau_{0}=\bar{\tau}$ (the optimal tariff), then we would expect this term to be affected (negatively) by the lagged level of the HHI, which appears in $\tau_{t-1}^{n}$ but not in $\bar{\tau}$. The final term involves further lags in declining orders of magnitude.

Table 3 shows the effects of changes in the HHI from 1983 to 1993 on changes in final bound tariffs, both specific and ad valorem, between the Tokyo and Uruguay Rounds. ${ }^{52}$ The tariff change data is from Limão (2006, 2007). We use Tobit to account for the fact that tariff changes are never positive. Without the lagged HHI level, the estimated effect is negative (increases in $\mathrm{HHI}$ are associated with deeper tariff cuts) in each case, though significant only for specific tariffs. In columns (5) and (10), we use a dummy variable, which equals one if the $\mathrm{HHI}$ increased or stayed the same between the two rounds, zero otherwise. This is

\footnotetext{
51 Baldwin's study of the Kennedy and Tokyo Rounds showed that less liberalization occurred in industries with greater levels of protection at the beginning of each round, controlling for labor characteristics, growth rates and import penetration ratios. A review of the literature on gradualism in trade agreements can be found in Bagwell and Staiger (2002).

52 We use the final bound tariffs for this analysis to ensure consistency across the two rounds in terms of data sources, product classification, and method of averaging, and because we lack data on specific rates for the complete Tokyo Round implementation period.
} 


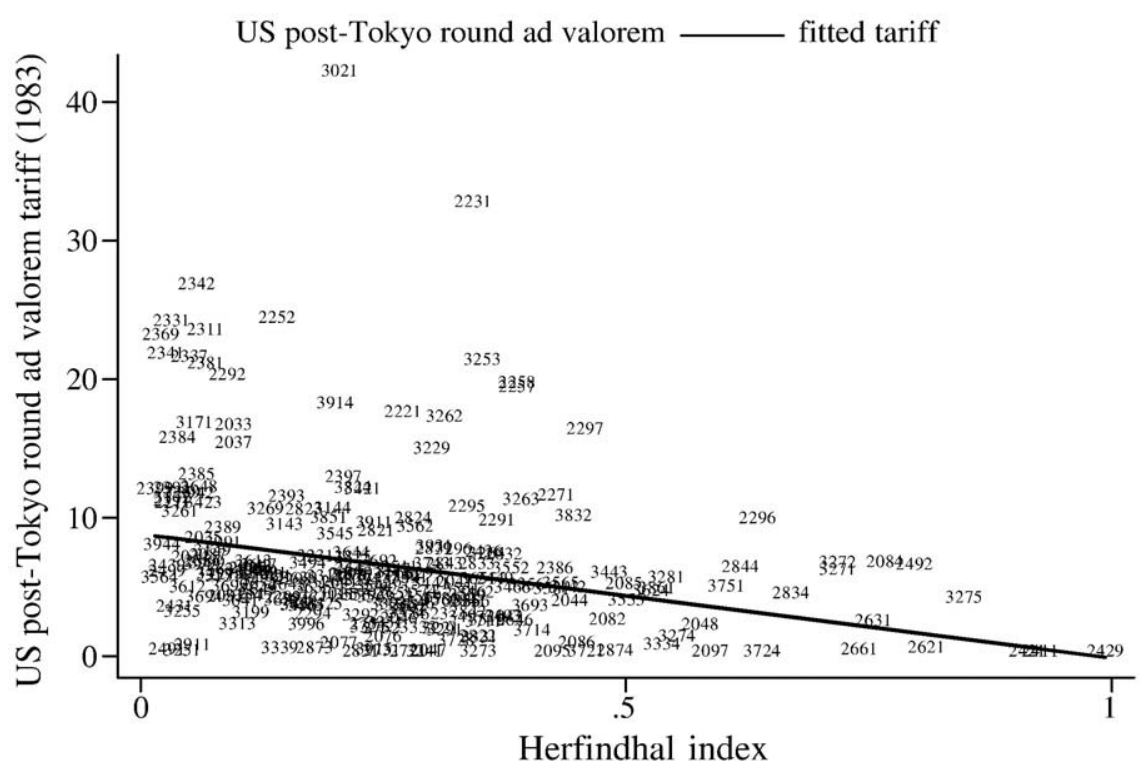

Fig. 3. Correlation between US tariffs and Herfindahl-Hirschman index, 1983.

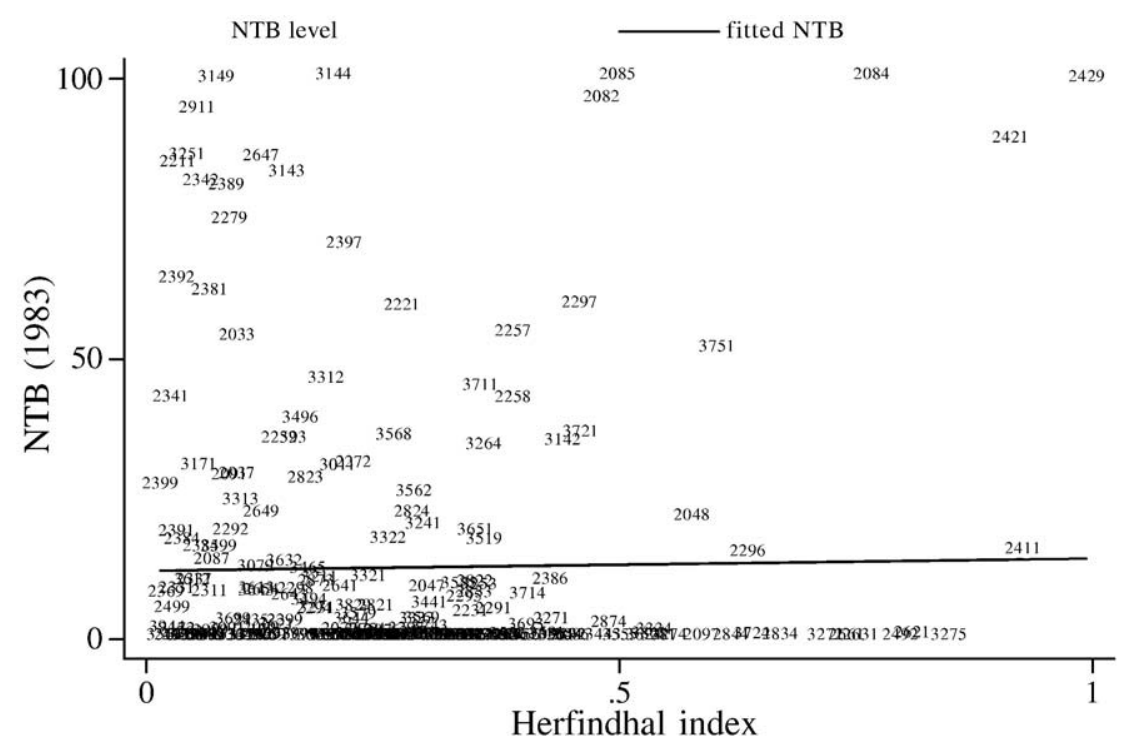

Fig. 4. Correlation between US NTBs and Herfindahl-Hirschman index, 1983.

motivated by Proposition 1, which implies that increases in HHI beyond that necessary to achieve full participation should have no effect on the tariff, and thus the sign of an $\mathrm{HHI}$ change may be of greater relevance than its absolute size. This finds support in the data, as the estimates are negative and significant for both types of tariff. In columns (4) and (9), we control for the 1983 level of the HHI. As expected, the change in HHI has a negative and significant effect on the tariff change, for both types of tariff, as does lagged HHI level. ${ }^{53}$

\section{Conclusion}

The theory presented in this paper makes basically two assertions. The first is that there should be a negative relationship between the tariff in an industry and the market share of the countries participating in negotiations over that tariff. The intuition is that the larger is this share, the greater is the share of the benefit from tariff reduction that is

\footnotetext{
53 Interestingly, the coefficient on FTA share becomes positive and significant for ad valorem tariffs, which is consistent with the findings of Limão (2006).
}

internalized by the negotiators. This is the most basic aspect of the MFN free-rider problem. The second assertion is that the market share of participants increases with the degree of concentration of the exporters in the industry. This stems from the fact that our optimal mechanism assigns participants according to a principal supplier rule.

Together these assertions produce a negative relationship between the tariff and the degree of concentration. We find strong evidence for this relationship for U.S. MFN tariffs, which is robust to the time period and level of aggregation considered, the introduction of controls, the use of instrumental variables, and the estimation of the model in both levels and changes. Moreover, it is not present for NTBs, despite the many common determinants of the two forms of protection. Given this preponderance of evidence and the absence of an alternative theory consistent with it, we conclude that the MFN free rider problem exists and that our theory describing it has merit.

There are several important directions in future research. One is to obtain direct evidence on participation, which would allow us to test the two assertions of our theory separately. Another is to expand the scope of the analysis beyond the U.S. to include a multitude of 
Table 3

The impact of free-riding on US MFN bound specific and ad valorem tariff rates across rounds (pre vs. post Uruguay Round)

\begin{tabular}{|c|c|c|c|c|c|c|c|c|c|c|}
\hline TOBIT & 1 & 2 & 3 & 4 & 5 & 6 & 7 & 8 & 9 & 10 \\
\hline \multirow[t]{2}{*}{ Dependent variable } & \multicolumn{5}{|c|}{ Change US MFN bound specific tariff } & \multicolumn{5}{|c|}{ Change US MFN bound ad valorem tariff } \\
\hline & \multicolumn{5}{|c|}{ 4-digit SIC (1987) } & \multicolumn{5}{|c|}{ 4-digit SIC (1987) } \\
\hline \multirow{2}{*}{ Change Herfindahl-Hirschman index } & -0.03 & -0.06 & -0.05 & -0.06 & & -1.02 & -0.71 & -0.68 & -1.7 & \\
\hline & 0.02 & $0.04+$ & $0.03 *$ & $0.03^{*}$ & & 0.77 & 0.71 & 0.69 & $0.69 *$ & \\
\hline \multirow[t]{2}{*}{ Dichotomous change Herfindahl-Hirschman index } & & & & & -0.01 & & & & & -0.45 \\
\hline & & & & & $0.00 * *$ & & & & & $0.24+$ \\
\hline \multirow[t]{2}{*}{ Change FTA share } & & -0.02 & -0.03 & -0.03 & -0.03 & & 0.88 & 0.76 & 1.25 & 0.73 \\
\hline & & 0.02 & $0.02+$ & $0.02+$ & $0.02+$ & & 0.67 & 0.66 & $0.69+$ & 0.64 \\
\hline \multirow[t]{2}{*}{ Change share of US exports to top 5 exporters } & & & -0.07 & -0.07 & -0.07 & & & -2.05 & -2.09 & -2.08 \\
\hline & & & $0.03^{*}$ & $0.03 *$ & $0.03^{*}$ & & & 1.28 & 1.27 & 1.27 \\
\hline \multirow[t]{2}{*}{ Herfindahl-Hirschman index pre UR } & & & & -0.01 & & & & & -2.39 & \\
\hline & & & & 0.02 & & & & & $0.76 * *$ & \\
\hline \multirow[t]{2}{*}{ Constant } & -0.01 & 0 & -0.01 & -0.01 & 0 & -2.36 & -2.54 & -2.72 & -2.22 & -2.5 \\
\hline & $0.00^{* *}$ & 0.01 & $0.00 *$ & 0 & 0 & $0.12 * *$ & $0.18^{* *}$ & $0.21 * *$ & $0.25^{* *}$ & $0.25^{* *}$ \\
\hline Change inverse import penetration ratio*2-digit DV & No & Yes & Yes & Yes & Yes & No & Yes & Yes & Yes & Yes \\
\hline Observations & 63 & 63 & 63 & 63 & 63 & 181 & 181 & 181 & 181 & 181 \\
\hline
\end{tabular}

Robust standard errors are presented under each estimated coefficient.

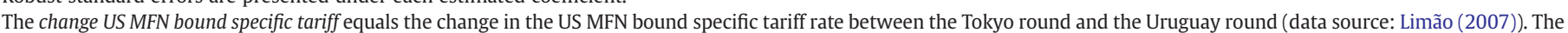

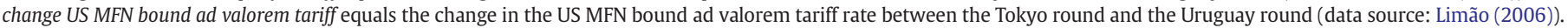

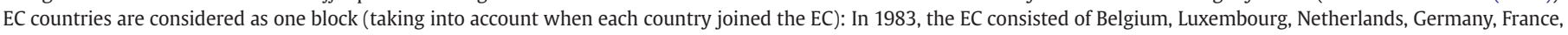
Italy, Denmark, Ireland, United Kingdom, Cyprus, and Greece. By 1993, Portugal and Spain had joined.

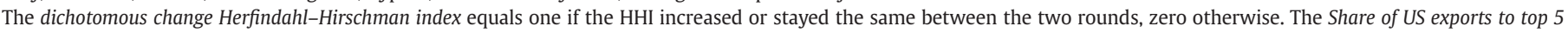

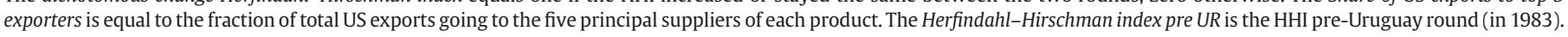
See definitions of remaining variables at the end of Table 1.

countries, so as to test the generality of the MFN free-rider effect and attempt to add up the global impact of MFN. According to the model, the severity of the MFN free rider effect should be greater for markets in which the importer has greater monopoly power in trade. This requires taking into account measures of monopoly power both across goods and across countries. Our follow-up paper Ludema and Mayda (2008b) is a first attempt at this. A third is to build on our U.S. estimates showing that tariffs are lower on products imported principally from major U.S. export destinations, suggesting that tariff concessions reflect considerations of reciprocity. To model this would require expanding the dimensionality of the existing theoretical model to accommodate many countries with interdependent tariff schedules.

Finally, as mentioned in the introduction, there are many benefits to MFN discussed in the literature, so it would be premature to advocate the elimination of MFN based on our results. The solution to the MFN free rider problem is to provide greater inducements for participation and/or isolate free riders from the benefits of liberalization. The principal supplier rule, reciprocity, the use of formula negotiations and the single undertaking can all be seen as attempts to combat the MFN free rider problem along one or both of these dimensions. At this point, all we know is that they haven't eliminated the problem. More study is required to determine what effects these approaches have had and to suggest preferable alternatives.

\section{Appendix A}

\section{A.1. Proof of Proposition 1}

To establish the first claim, we note that if $H=1$, then $\theta_{1}=1$, which implies that $\Omega(N)=w^{*}\left(\tau^{w}\right)-w^{*}(\bar{\tau})-\left[w_{0}(\bar{\tau})-w_{0}\left(\tau^{w}\right)\right]>0$. Thus, $\tau^{w}$ can be implemented. To establish the second claim, note that by the Mean Value Theorem, there exists a tariff $\tau_{i} \in\left[\tau^{w}, \tau^{n}(N / i)\right]$ such that $w_{i}\left(\tau^{w}\right)-w_{i}\left(\tau^{n}(N / i)=\theta_{\mathrm{i}}^{2} v\left(\tau_{i}\right)\right.$ for all $i$, where $v(\tau) \equiv-\left(w^{* \prime}(\tau)\right)^{2} /\left(w_{0}{ }^{\prime \prime}(\tau)+\right.$ $\left.w^{* \prime \prime}(\tau)\right)^{2}>0$. Letting $\bar{v}$ denote maximum value of $v(\tau)$ on the support $\left[\tau^{w}, \bar{\tau}\right]$, it follows that,

$H \bar{v} \geq \sum_{i \in N} w_{i}\left(\tau^{w}\right)-w_{i}\left(\tau^{n}(N \backslash i)\right)$

Thus, if $H \bar{v}<w_{0}(\bar{\tau})-w_{0}\left(\tau^{w}\right), \Omega(N)<0$ and $\tau^{w}$ cannot be implemented.

\section{A.2. Proof of Proposition 2}

Suppose $\tilde{\tau}$ is feasible under PSR, and let $B$ be the PSR set such that $\tilde{\tau}=\tau^{n}(B)$. For $B$ to be an equilibrium set of participants, we need that,

$$
\sum_{i \in B} w_{i}(\tilde{\tau})-w_{i}\left(\tau^{n}(B \backslash i)\right) \geq \sum_{i \in \tilde{A}} w_{i}(\tilde{\tau})-w_{i}\left(\tau^{n}(\tilde{A} \backslash i)\right)
$$

or

$$
\sum_{i \in B} \int_{\tilde{\tau}}^{\tau^{n}(B \backslash i)} \theta_{i} w^{\prime}(\tau) d \tau \geq \sum_{i \in \tilde{A}} \int_{\tilde{\tau}}^{\tau^{n}(\tilde{A} \backslash i)} \theta_{i} w^{\prime}(\tau) d \tau
$$

The left-hand side of this inequality can be written as,

$\sum_{i \in B \backslash \hat{i}} \int_{\tau^{n}(B \backslash \hat{i})}^{\tau^{n}(B \backslash i)} \theta_{i} w^{\prime}(\tau) d \tau+\int_{\tilde{\tau}}^{\tau^{n}(B \backslash \hat{i})} \Theta_{B} w^{\prime}(\tau) d \tau$

while the right-hand side is strictly less than,

$\sum_{i \ni \theta_{i}>\theta_{\hat{i}}} \int_{\tau^{n}(B \backslash \hat{i})}^{\tau^{n}(\tilde{A} \backslash i)} \theta_{i} W^{\prime}(\tau) d \tau+\int_{\tilde{\tau}}^{\tau^{n}(B \backslash \hat{i})} \Theta_{\tilde{A}} W^{\prime}(\tau) d \tau$

This last point follows from fact that $A$ must contain elements with smaller market share than that of the critical exporter in $B$. Now given that $\Theta_{B}=\Theta_{\tilde{A}}$ by definition, a sufficient condition for $B$ to be an equilibrium set is,

$\sum_{i \ni B \backslash \hat{i}} \int_{\tau^{n}(B \backslash \hat{i})}^{\tau^{n}(B \backslash i)} \theta_{i} w^{\prime}(\tau) d \tau \geq \sum_{i \ni \theta_{i}>\theta_{\hat{i}}} \int_{\tau^{n}(B \backslash \hat{i})}^{\tau^{n}(\tilde{A} \backslash i)} \theta_{i} w^{\prime}(\tau) d \tau$

This must hold, because $B$ contains all exporters such that $\theta_{i}>\theta_{i}$, while $\tilde{A}$ does not. Now considering that $B$ is a PSR equilibrium set, and $\hat{\tau}$ is the minimum implementable PSR tariff, it must be that $\tilde{\tau}=\tau^{n}(B) \geq \tilde{\tau}$. But if $\tilde{\tau}>\hat{\tau}$, then $\tilde{\tau}$ is not the minimum implementable tariff, which is a contradiction. Hence, $\tilde{\tau}=\hat{\tau}$.

If $\tilde{\tau}$ is not feasible under PSR, then it must lie strictly between two PSR tariffs. Let $C$ and $D$ denote, respectively, the largest and smallest PSR sets such that $\tau^{n}(C)>\tilde{\tau}>\tau^{n}(D)$. Now consider a hypothetical country $k$ such 
that $\theta_{k}=\Theta_{\tilde{A}}-\Theta_{C}$. It is straightforward that $\Omega(\tilde{A})-\Omega(C)<\Omega(C \cup k)-\Omega(C)$. Convexity implies,

$[\Omega(C \cup k)-\Omega(C)] \theta_{\hat{i}_{D}} \leq[\Omega(D)-\Omega(C)] \theta_{k}$

or

$\Omega(\tilde{A})<\Omega(C \cup k) \leq\left(\theta_{k} / \theta_{\hat{i}_{D}}\right) \Omega(D)+\left(1-\theta_{k} / \theta_{\hat{i}_{D}}\right) \Omega(C)$

By definition $\Omega(\tilde{A}) \geq 0, \Omega(D)<0$ and $0<\theta_{k} / \theta_{\hat{i}_{D}}<1$. Thus, $\Omega(C)>0$. But this means that $C=\hat{A}$ and $D=\hat{A}^{+}$, so $\hat{\tau}>\tilde{\tau}>\hat{\tau}^{+}$. Finally, the fact that $\hat{\tau}^{+} \rightarrow \hat{\tau}$ as $\theta_{i^{+}} \rightarrow 0$ implies $\tilde{\tau} \rightarrow \hat{\tau}$.

\section{A.3. Proof of Proposition 3}

Let $\hat{x}_{1}$ be optimal value of $x$ under $\Theta_{1}$, and consider $x^{\prime}$ such that $\Theta_{0}\left(x^{\prime}\right)=\Theta_{1}\left(\hat{x}_{1}\right)$. If we can show that $\hat{x}_{0}<x^{\prime}$, then we will have proven that the equilibrium market share of participants is higher, and the tariff is lower, under $\Theta_{1}$ than under $\Theta_{0}$. We show $\hat{x}_{0}<x^{\prime}$ by establishing that at $x^{\prime}$ the participation constraint (13) is violated. Since the negotiated tariff is at $x^{\prime}$ under $\Theta_{0}$ is the same as at $\hat{x}_{1}$ under $\theta_{1}$ by construction, we need only show that, $h_{0}\left(x^{\prime}\right)<h_{1}\left(\hat{x}_{1}\right)$. This condition can be written as,

$h_{0}\left(\hat{x}_{1}\right)+\sum_{i=\hat{x}_{1}}^{x^{\prime}} \theta_{0}(i)^{2}<h_{1}\left(\hat{x}_{1}\right)$

We know that,

$\sum_{i=\hat{x}_{1}}^{x^{\prime}} \theta_{0}(i)^{2} \leq \theta_{0}\left(\hat{x}_{1}\right) \sum_{i=\hat{x}_{1}}^{x^{\prime}} \theta_{0}(i)$

which follows from the fact that $\theta_{0}(i)$ is decreasing (as we have ordered the countries in descending order of market share). Similarly, $\Theta_{0}\left(x^{\prime}\right)=\Theta_{1}\left(\hat{x}_{1}\right)$ can be written as, $\Theta_{0}\left(\hat{x}_{1}\right)+\sum_{\hat{x}_{1}}^{x^{\prime}} \theta_{0}(i)=\Theta_{1}\left(\hat{x}_{1}\right)$. Combining these equations, a sufficient condition for $\hat{x}_{0}<x^{\prime}$ becomes,

$\sum_{i=1}^{\hat{x}_{1}}\left[\theta_{1}(i)^{2}-\theta_{0}(i)^{2}\right]-\theta_{0}\left(\hat{x}_{1}\right)\left[\Theta_{1}\left(\hat{x}_{1}\right)-\Theta_{0}\left(\hat{x}_{1}\right)\right]>0$

This condition can be re-written as,

$$
\begin{aligned}
\sum_{i=1}^{\hat{x}_{1}}[ & \left.\theta_{1}(i)^{2}-\theta_{0}(i)^{2}\right]-\theta_{0}\left(\hat{x}_{1}\right)\left[\Theta_{1}\left(\hat{x}_{1}\right)-\Theta_{0}\left(\hat{x}_{1}\right)\right] \\
= & \theta_{1}\left(\hat{x}_{1}\right)\left[\Theta_{1}\left(\hat{x}_{1}\right)-\Theta_{0}\left(\hat{x}_{1}\right)\right] \\
& +\sum_{i=1}^{\hat{x}_{1}-1}\left[\theta_{1}(i)+\theta_{0}(i)-\theta_{1}(i+1)-\theta_{0}(i+1)\right]\left[\Theta_{1}(i)-\Theta_{0}(i)\right]>0
\end{aligned}
$$

which must hold, because $\theta_{1}(i)$ and $\theta_{1}(i)$ are decreasing in $i$, and $\Theta_{1}(i)-$ $\Theta_{0}(i)>0$ for all $i$.

The final part of the Proposition 3 is that $H_{1}>H_{0}$. This follows from the same decomposition we used above, namely,

$$
\begin{aligned}
H_{1}-H_{0}= & {\left[\theta_{1}(N)+\theta_{0}(N)\right]\left[\Theta_{1}(N)-\Theta_{0}(N)\right] } \\
& +\sum_{i=1}^{N-1}\left[\theta_{0}(i)+\theta_{1}(i)-\theta_{0}(i+1)-\theta_{1}(i+1)\right]\left[\Theta_{1}(i)-\Theta_{0}(i)\right]>0 .
\end{aligned}
$$

\section{References}

Bagwell, K., Staiger, R.W., 2002. The Economics of the World Trading System. MIT Press, Cambridge, MA.

Bagwell, K., Staiger, R.W., 2004. Backward stealing and forward manipulation in the WTO. NBER Working Paper No. 10420.

Bagwell, K., Staiger, R.W., 2005. Enforcement, private political pressure and the GATT/ WTO escape clause. Journal of Legal Studies 34, 471-514.
Baldwin, R., 1987. Politically realistic objective functions and trade policy: PROFs and tariffs. Economic Letters 24, 287-290

Blonigen, B.A., Bown, C.P., 2003. Antidumping and retaliation threats. Journal of International Economics 60, 249-273.

Bond, E.W., Ching, S., Lai, E., 2003. Game-theoretic analysis of China's accession to the WTO. Pacific Economic Review 8, 117-125.

Bown, C.P., 2004. Trade disputes and the implementation of protection under the GATT: an empirical assessment. Journal of International Economics 62, 263-294.

Broda, C., Limão, N., Weinstein, D., 2008. Optimal tariffs and market power: the evidence. American Economic Review 98, 2032-2065.

Caplin, A., Krishna, K., 1988. Tariffs and the most-favored-nation clause: a game theoretic approach. Seoul Journal of Economics 1, 267-289.

Choi, J.P., 1995. Optimal tariffs and the choice of technology: discriminatory tariffs vs the most favored nation clause. Journal of International Economics 38, 143-160.

Dixit, A., Olson, M., 2000. Does voluntary participation undermine the Coase theorem? Journal of Public Economics 76, 309-335.

Ederington, J., McCalman, P., 2003. Discriminatory tariffs and international negotiations Journal of International Economics 61, 397-424.

Ethier, W.J., 2004. Reciprocity, nondiscrimination, and a multilateral world. Review of International Economics 12, 303-320.

Feenstra, R.C., 1997. NBER trade database, disk 3: U.S. exports, 1972-1994, with state exports and other U.S. data. NBER Working Paper no. 5990.

Finger, J.M., 1979. Trade liberalization: a public choice perspective. In: Amacher, R.C. Haberler, G., Willet, T.D. (Eds.), Challenges to a Liberal International Economic Order. American Enterprise Institute, Washington, DC.

Finger, J.M., Reincke, U., Castro, A., 2002. Market access bargaining in the Uruguay round: how tightly does reciprocity bind? In: Bhagwati, Jagdish N. (Ed.), On Going Alone: The Case for Relaxed Reciprocity in Freeing Trade. MIT Press, Cambridge, MA

Gawande, K., Bandyopadhyay, U., 2000. Is protection for sale? evidence on the Grossman-Helpman theory of endogenous protection. Review of Economics and Statistics 82, 139-152.

Gawande, K., Krishna, P., Robbins, M.J., 2006. Foreign lobbies and U.S. trade policy. Review of Economics and Statistics 88, 563-571.

Goldberg, P.K., Maggi, G., 1999. Protection for sale: an empirical investigation. American Economic Review 89, 1135-1155.

Grossman, G.M., Helpman, E., 1994. Protection for sale. American Economic Review 84, 833-850.

Grossman, G.M., Helpman, E., 1995. Trade wars and trade talks. Journal of Political Economy 103, 675-708.

Hoda, A., 2001. Tariff Negotiations and Renegotiations under the GATT and the WTO: Procedures and Practices. Cambridge University Press, Cambridge.

Horn, H., Mavrodis, P.C., 2001. Economic and legal aspects of the most-favored-nation clause. European Journal of Political Economy 17, 233-279.

Jackson, J.H., 1997. The World Trading System: Law and Policy of International Economic Relations. MIT Press, Cambridge, MA.

Johnson, H., 1965. An economic theory of protectionism, tariff bargaining, and the formation of customs unions. Journal of Political Economy 73, 256-283.

Karacaovali, B., Limao, N., 2008. The Clash of Liberalizations: Preferential vs. Multilateral Trade Liberalization in the European Union. Journal of International Economics 74, 299-327.

Lavergne, R.P., 1983. The Political Economy of U.S. Tariffs. Academic Press, New York.

Limão, N., 2006. Preferential trade agreements as stumbling blocks for multilateral trade liberalization: evidence for the U.S. American Economic Review 96, 896-914.

Limão, N., 2007. Are preferential trade agreements with non-trade objectives a stumbling block for multilateral liberalization? Review of Economic Studies 74, 821-855.

Ludema, R.D., 1991. International trade bargaining and the most-favored-nation clause Economics and Politics 3,1-20.

Ludema, R.D. Cebi, P. 2005. The rise and fall of the most-favored nation clause. In: Cebi, P. (Ed.), Essays on the political economy of international trade. PhD Dissertation, Georgetown University, pp. 6-37.

Ludema, R.D., Mayda, A.M., 2008a. Do countries free ride on MFN? Working paper 08-04 Georgetown University.

Ludema, R.D., Mayda, A.M., 2008b. The free rider effect of the most-favored nation clause: evidence across countries and commodities. Mimeo. Georgetown University.

McCalman, P., 2002. Multi-lateral trade negotiations and the most favored nation clause. Journal of International Economics 57, 151-176.

Nicita, A., Olarreaga, M., 2001. Trade and production, 1976-99. Documentation of Trade and Production Database: www.worldbank.org/research/trade, World Bank, November 2001

Palfrey, T.R., Rosenthal, H., 1984. Participation and the provision of discrete public goods: a strategic analysis. Journal of Public Economics 24,171-193.

Preeg, E.H., 1970. Traders and Diplomats: A History and Analysis of the Kennedy Round of Negotiations Under the GATT. The Brookings Institution, Washington.

Rose, A.K., 2004. Do we really know that the WTO increases trade? American Economic Review 94, 98-114.

Saggi, K., 2004. Tariffs and the most favored nation clause. Journal of International Economics 63, 341-368.

Saijo, T., Yamato, T., 1999. A voluntary participation game with a non-excludable public good. Journal of Economic Theory 84, 227-242.

Trefler, D., 1993. Trade liberalization and the theory of endogenous protection: an econometric study of U.S. import policy. The Journal of Political Economy 101,138-160.

Viner, J., 1924. The most-favored-national clause in American commercial treaties. Journal of Political Economy 32, 101-129.

Viner, J., 1931. The most-favored-national clause. Index, Svenska Handelsbanken, Stockholm. Reprinted in: Viner, J., 1951. International Economics. Glencoe, IL, The Free Press. 